Article

\title{
Towards the Development of a Probabilistic Approach to Informal Settlement Fire Spread Using Ignition Modelling and Spatial Metrics
}

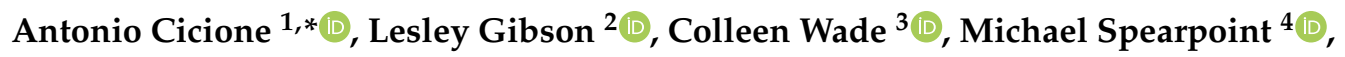 \\ Richard Walls ${ }^{1}$ (D) and David Rush ${ }^{2}$ (D) \\ 1 Department of Civil Engineering, Stellenbosch University, Private Bag X1, Matieland 7602, Stellenbosch, \\ South Africa; rwalls@sun.ac.za \\ 2 School of Engineering, University of Edinburgh, Edinburgh EH9 3JL, UK; Lesley.gibson@ed.ac.uk (L.G.); \\ d.rush@ed.ac.uk (D.R.) \\ 3 Fire Research Group Ltd., Christchurch 8023, New Zealand; colleen.wade@fireresearchgroup.com \\ 4 OFR Consultants, Sevendale House, Lever St., Manchester M1 1JA, UK; \\ michael.spearpoint@ofrconsultants.com \\ * Correspondence: acicione@sun.ac.za
}

Received: 5 October 2020; Accepted: 6 November 2020; Published: 15 November 2020

\begin{abstract}
Large conflagrations of informal settlements occur regularly, leaving thousands of people homeless daily and taking tens of thousands of lives annually. Over the past few years, a large amount of data has been collected from a number of full-scale informal settlement fire experiments. This paper uses that data with a semi-probabilistic fire model previously proposed by the authors, to illustrate the potential applications of the fire spread method proposed. The current model is benchmarked against a 20-dwelling full-scale informal settlement fire experiment, and the effects of the (a) ignition criteria, (b) wind direction, and (c) wind speeds on the predicted fire spread rates are investigated through the use of a parametric study. Colour maps of the fire spread rates and patterns are then used to visually interpret the effects of different types of fire scenarios and fire breaks. Finally, the fire spread capability within B-RISK is used to derive a linear equation for the potential fire spread rate as a function of the settlement spatial metrics (e.g., density and distance to nearest neighbour). To further illustrate the potential application of this work, the fire spread rate equation is then applied across the whole of Cape Town, South Africa, to show the 10 informal settlement areas most at "risk" of large conflagrations.
\end{abstract}

Keywords: informal settlements; fire spread; ignition; spatial metrics; B-RISK; probabilistic simulation

\section{Introduction}

Informal settlements, also known as shantytowns or slums, are settlements that are typically not formally planned and consist of makeshift structures built on land that has not been designated for residential use. These structures, more commonly known as shanties, shacks or informal settlement dwellings (ISDs), are typically built from materials that are immediately available in the inhabitants' surroundings, many of which are combustible. Informal settlements are extremely vulnerable to large conflagrations as a result of these combustible structures coupled with the close proximity at which these dwellings are built and prevailing weather conditions.

In South Africa alone there are more than 5000 ISD fires per annum, and the number of fires is increasing annually [1]. According to the World Health Organization (WHO), fires cause approximately 180,000 deaths globally per annum, with the majority of those deaths and associated burn injuries occurring in low- and middle-income countries [2]. Figure 1 depicts a fire that occurred in 2016 in 
the Estrada de Alpina favela of São Paulo, Brazil, which destroyed hundreds of informal homes [3]. Figure 2 depicts a fire that occurred in 2017 in the Imizamo Yethu informal settlement in Hout Bay, South Africa, which destroyed more than 2100 homes and left approximately 9700 people homeless [4].

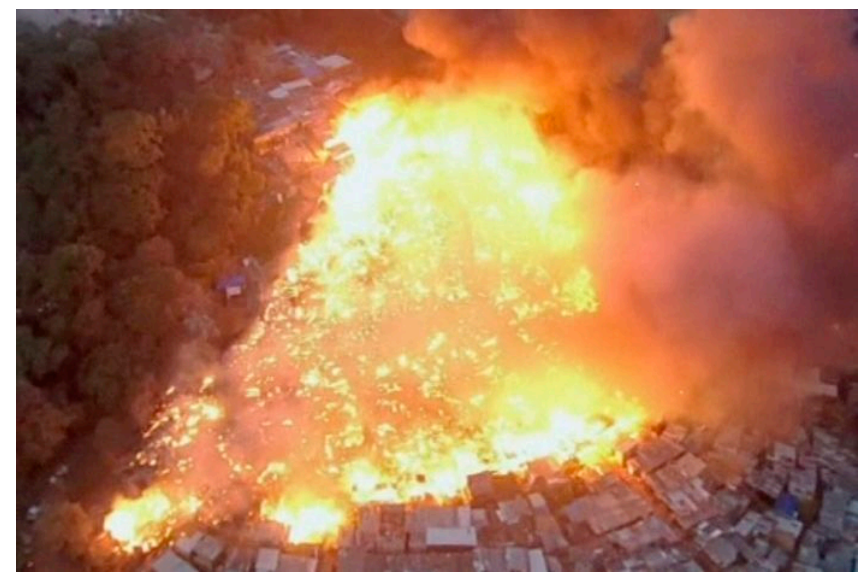

Figure 1. Fire in the Estrada de Alpina favela of São Paulo [3].

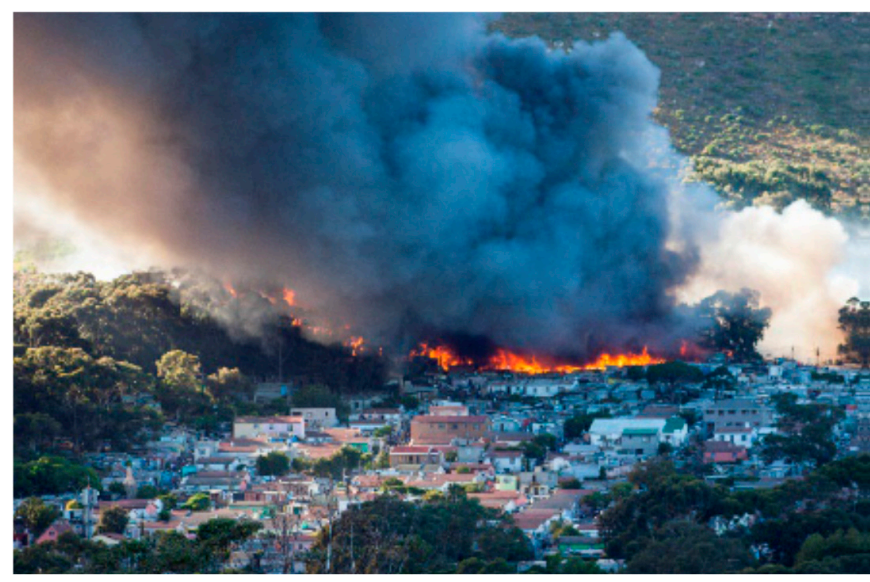

Figure 2. Imizamo Yethu informal settlement fire [4]. With permission from Ryan Heydenrych.

The study of informal settlement fires is a relatively new research field. Previous research has set out to better understand ISD enclosure fire dynamics (individual scale) and informal settlement fire dynamics (macro scale). A number of large-scale ISD experiments have been conducted [5-9], ranging from single dwellings to 20 dwellings in a single burn. In previous work, simulations using Fire Dynamics Simulator (FDS) have been undertaken to demonstrate the software's ability to predict the fire behaviour of single-dwelling fires [7]. However, these comprehensive simulations took weeks to run on the high-performance computer of Stellenbosch University, which made it impractical to run scenarios consisting of multiple dwellings. Cicione et al. [6] proposed some simplifications that were incorporated into those FDS simulations, which significantly reduced the computational time needed to run the multiple-dwelling cases. However, the simplified simulations were found to be extremely sensitive to the input parameters and, although the simplifications reduced the computational requirements, the time needed to simulate entire settlement scenarios would still be impractical.

As an alternative, Cicione et al. [10] have developed a preliminary semi-probabilistic model of informal settlement fire spread using B-RISK (a two-zone fire modelling software tool). The aim was to take the first step towards developing a tool that could assist authorities of countries with large informal settlements to provide predictive capabilities that can help in identifying high-risk areas or quantify the magnitude of an incident to which municipalities may need to respond. The semi-probabilistic modelling approach [10] showed promising results compared to a triple ISD experiment and to the 
Imizamo Yethu informal settlement fire that occurred in 2017. In order to capture a more realistic fire spread behaviour that occurs in settlements due to their high variability, the ISDs should not only be randomly selected based on floor area (as done by Cicione et al. [10]) but also based on the cladding/lining material (as discussed in this paper) and their expected heat-release rates.

Using spatial analysis with Geographic Information Systems (GIS), the layout of informal settlements and the spatial arrangement of individual dwellings relative to each other (referred to as spatial metrics) have been postulated to be indicative of fire spread risk. The identified fire spread risk spatial metrics can then be applied to settlements so that those most at risk of fire spread can be identified. For example, Gibson et al. [11] used burn areas identified from satellite imagery to empirically obtain the spatial metric values of settlements from their dwellings within the burn areas. Settlements with similar spatial metric values were then identified within a broader environment and were postulated to be at a high risk of fire spread. This approach relies on threshold values (75th percentile values of spatial metrics found in the burn areas) to identify either settlements that are at higher risk of fire spread or those that are not. This binary approach is simplistic, where in reality all settlements are at some risk of fire spread and thus a more nuanced, fire science-based approach is needed.

It is against this backdrop that this paper seeks to:

1. Further investigate the semi-probabilistic model of informal settlement fire spread using B-RISK, as proposed by Reference [10], by

a. investigating the effect of the ignition properties (i.e. the Flux-Time Product $(F T P)$ index, FTP value and the critical heat flux (CHF)) assigned to ISDs in B-RISK, by comparing the simulation results to a full-scale 20-dwelling informal settlement fire experiment [8];

b. post-processing the B-RISK time-to-ignition output data, to plot colour maps of the fire spread rates of the settlement under consideration, allowing end users to better interpret the results.

2. Derive an equation for potential fire spread rate as a function of the settlement spatial metrics by

a. applying the semi-probabilistic approach using B-RISK (i.e., randomly populating different informal settlement scenarios) to determine which spatial metrics (i.e., dwelling density, edge density, etc.) pose the highest risk to informal settlement fire spread, which are then used to derive a fire spread rate equation;

b. applying the equation to all informal settlements across the whole of Cape Town, to identify the ten, larger than 1 ha, that are most at risk of fire spread, based on this semi-probabilistic approach.

\section{Radiation and Ignition of Secondary Items in B-RISK}

B-RISK is a two-zone model [12] that is typically used to simulate fire and smoke within enclosures bounded by walls and ceilings. B-RISK calculates the ignition of secondary items as a result of radiation from either one or more burning items or from the hot gas layer within the enclosure. This section gives a brief review of the radiation and ignition submodels employed in B-RISK, but for more information, the reader should refer to the user guide and technical manual [13]. The radiation heat-transfer method employed by B-RISK has been studied in depth and has been found to be a suitable method for a variety of cases. Sazegara et al. [14] benchmarked the single-item ignition prediction capability of B-RISK using results from a furniture calorimeter against room-size experiments. The method has also showed promise in other fields, e.g., Tohir and Spearpoint [15] have simulated the Building Research Establishment (BRE) multiple vehicle fire spread experiment [16].

In this work, the item-to-item submodel of B-RISK is used to simulate the fire spread between the ISDs, which is a novel application for which the software was never originally designed for. To simulate the spread between the ISDs in B-RISK, the dwellings are simplified to items (as in Reference [10]) and treated as being "outside", with the settlement being simplified to a "room" that is fully open 
(i.e., a room with five vents the size of the room boundaries to allow all the hot gases to escape to the "outside"). This effectively removes the "zone" element from the zone model, but still keeping the radiation and ignition submodels, which is a convenient means of using these submodels rather than recreating them from scratch as a standalone tool. In this paper, the same approach is followed. Hence, there will be no hot layer build-up and the focus will be on item-to-item ignition (in other words, ISD-to-ISD fire spread).

\subsection{Radiation}

B-RISK (version 2019.043) employs the Point Source Method (PSM) in the Design Fire Generator (DFG) submodel as its default flame radiation model and this can be described mathematically with the following equation [13]:

$$
\dot{q}_{f}^{\prime \prime}=\frac{\dot{Q} \chi_{r} \cos \theta}{4 \pi R^{2}}
$$

where $\dot{q}_{f}^{\prime \prime}$ is the radiant heat flux, measured in $\mathrm{kW} / \mathrm{m}^{2}$, received by the target item from the flaming burning item; $\dot{Q}$ is the total heat release rate, measured in $\mathrm{kW}$, of the burning item; $\chi_{r}$ is the radiative fraction; $\theta$ is the angle between the radial distance $(R)$ and an imaginary line parallel to the floor where $R$ intersects with the target item, as depicted in Figure 3; and $R$ is the radial distance, measured in metres, from the centre of the flaming region of the burning item to the nearest point of the target item. Figure 3 depicts the geometry assumed in this paper and also visually illustrates the variables used in Equation (1). In the B-RISK implementation, $R$ will always be the plan-view distance so that theta will be zero.

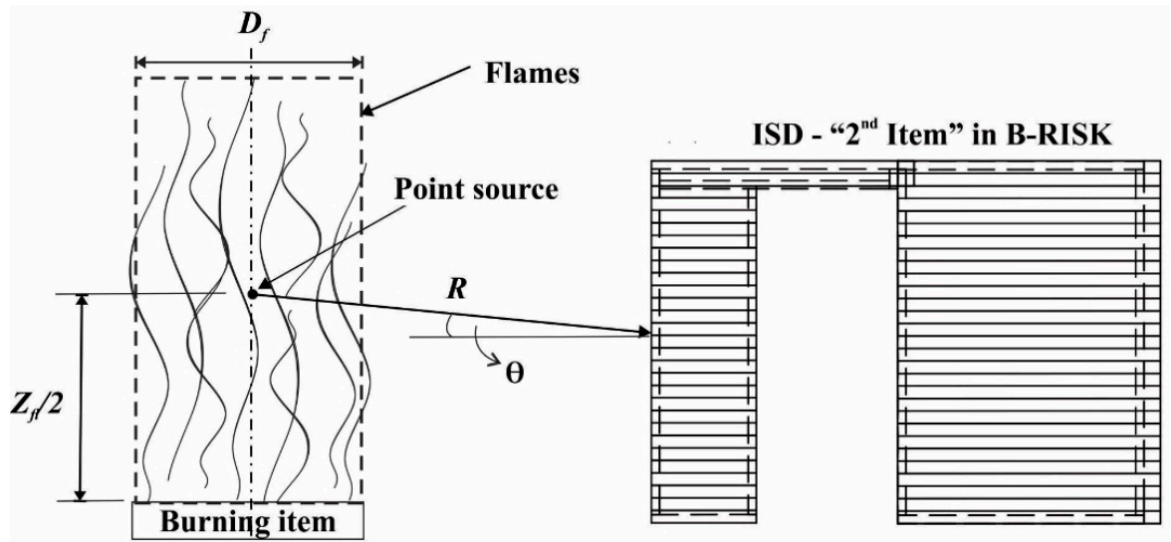

Figure 3. Point Source Method (PSM) geometry between the burning and target items [10]. Used with permission from Elsevier.

Since the flames from a real burning ISD ensue from door and window openings, in addition to flames that develop through the roof of the structure, the fire is assumed to originate from the base of the ISD for the PSM. The flame height $z_{f l}$ (Figure 3), measured in metres, is calculated using Heskestad's [17] flame height correlation given by the following formula:

$$
z_{f l}=0.235 \dot{Q}^{2 / 5}-1.02 D_{f}
$$

where $D_{f}$ is the width of the burning item (m). Cicione et al. [10] added the functionality to B-RISK to account for the effects of wind, by updating the radial distance $R$ to $R^{\prime}$, where $R^{\prime}$ is calculated as follows (refer to Figure 4):

$$
R^{\prime}=R-\frac{z_{f l}}{2} \cdot \sin \alpha
$$


where $\alpha$ is the angle between the vertical line from the centre of the burning item to the intersection of the wind-tilted flame axis and is calculated as follows [18]:

$$
\tan \alpha=2.73 \operatorname{Fr}^{\frac{2}{5}} \cdot Q^{*-0.1(1+2.5 y)} \cdot\left(\frac{W}{r^{*}}\right)^{-0.5}
$$

where $F r$ is the Froude number given by $u^{2} / g D_{f}$ (where $\mathrm{u}$ is the wind speed $(\mathrm{m} / \mathrm{s}$ ) and is assumed to be constant through the height of the domain and that it is not affected by the terrain or the items, $D_{f}$ is the short length of the rectangular burning item $(\mathrm{m})$ and $\mathrm{g}$ is the acceleration due to gravity $\left.\left(\mathrm{m} / \mathrm{s}^{2}\right)\right) ; Q^{*}$ is the dimensionless heat-release rate given by $\dot{Q} /\left(\rho_{a} C_{p} T_{a} g^{1 / 2} D^{5 / 2}\right)$ (where $\dot{Q}$ is the heat-release rate $(\mathrm{kW}), \rho_{a}$ is the density of the ambient air $\left(\mathrm{kg} / \mathrm{m}^{3}\right), C_{p}$ is the specific heat at a constant pressure $(\mathrm{kJ} /(\mathrm{kg} \cdot \mathrm{K}))$ and Ta is the ambient temperature $(\mathrm{K})) ; y=2$ for $0.05<Q^{*}<0.38$ and $y=2 / 3$ for $0.38<Q^{*}<12.8$; $\mathrm{W}$ is the long length of the rectangular burning item; and $r^{*}=\sqrt{\text { burning item floor area } / \pi}$.

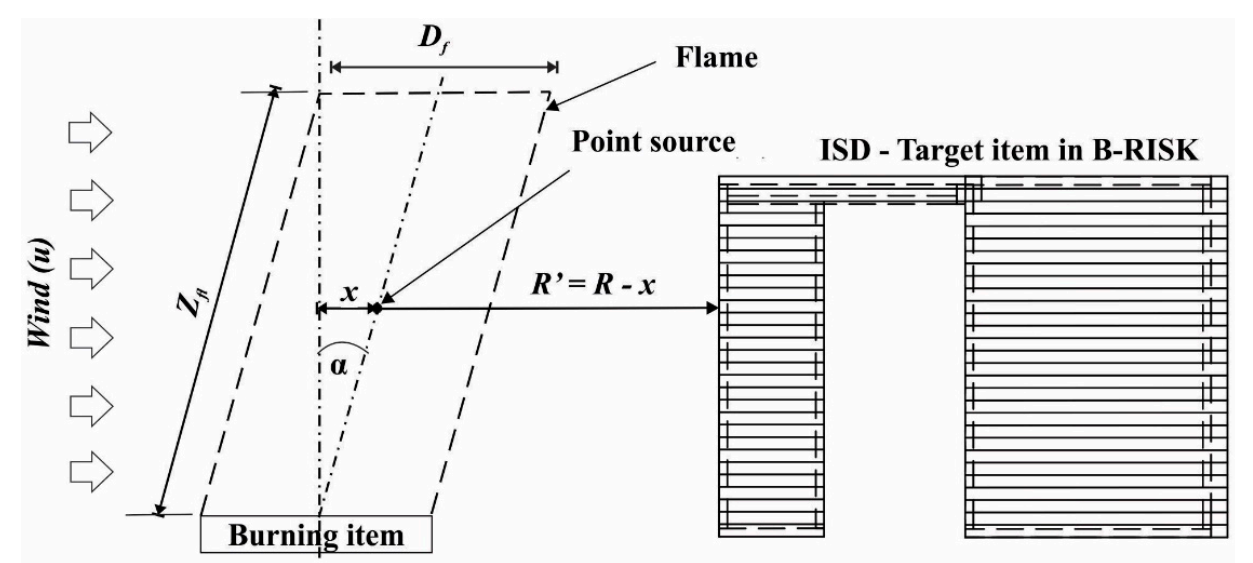

Figure 4. PSM geometry between the burning and target items with wind effects [10]. Used with permission from Elsevier.

Treating the ISDs as items and calculating the radiation emitted using the PSM (meaning an item can burn and flame from all sides equally) as employed by B-RISK is a simplification of reality. A fundamentally more correct method to calculate the incident radiation at a distance from a dwelling should consider the configuration factor of the actual wall geometry of the dwelling emitting the heat, such that

$$
\dot{q}_{i n c}^{\prime \prime}=\sigma \varnothing \varepsilon T^{4}
$$

where $\sigma$ is the Stefan-Boltzmann constant $\left(5.67 \times 10^{-11} \mathrm{~kW} /\left(\mathrm{m}^{2} \mathrm{~K}^{4}\right)\right)$; $\varnothing$ is the configuration factor between the emitter and target surface; $\varepsilon$ is the emissivity of the emitter; and $T$ is the temperature of the emitter (K). Each wall of the ISD will thus have a different emitted incident heat flux based on the arrangement of the wall (e.g., a wall with a window opening will radiate more energy compared to a wall with no openings). The radiation emitted from the ISDs is discussed on a fundamental level in Reference [19]. If a worst-case scenario is assumed (i.e., being conservative in this case), which will be the radiation in front of a door opening based on the findings from Reference [19], the radiation estimate can be calculated using the PSM and compared to the fundamental analytical approach in Equation (5), which gave a good correlation to the measured full-scale ISD experimental results. Consider the scenario on the left in Figure 5, i.e., the exact scenario of the experiment conducted by Reference [19], which then corresponds to the radiation versus distance curve on the right, which was calculated by Reference [19] using Equation (5). Where the radiation versus distance is calculated using Equation (1), as implemented by B-RISK, the separation distance is $R$ minus half the width of the dwelling, $\chi_{r}$ is taken as 0.3 for timber cribs from Table 3-4.14 of the SFPE Handbook [20], and $\dot{Q}$ is taken as the maximum measured heat release rate of $7 \mathrm{MW}$ [19], the curve in Figure 5 is obtained. 
Thus, from Figure 5, the correlation between the simplified method implemented in B-RISK and the analytical method as implemented by Reference [19] has a maximum deviation of $11.5 \%$ at a distance of $0.26 \mathrm{~m}$.
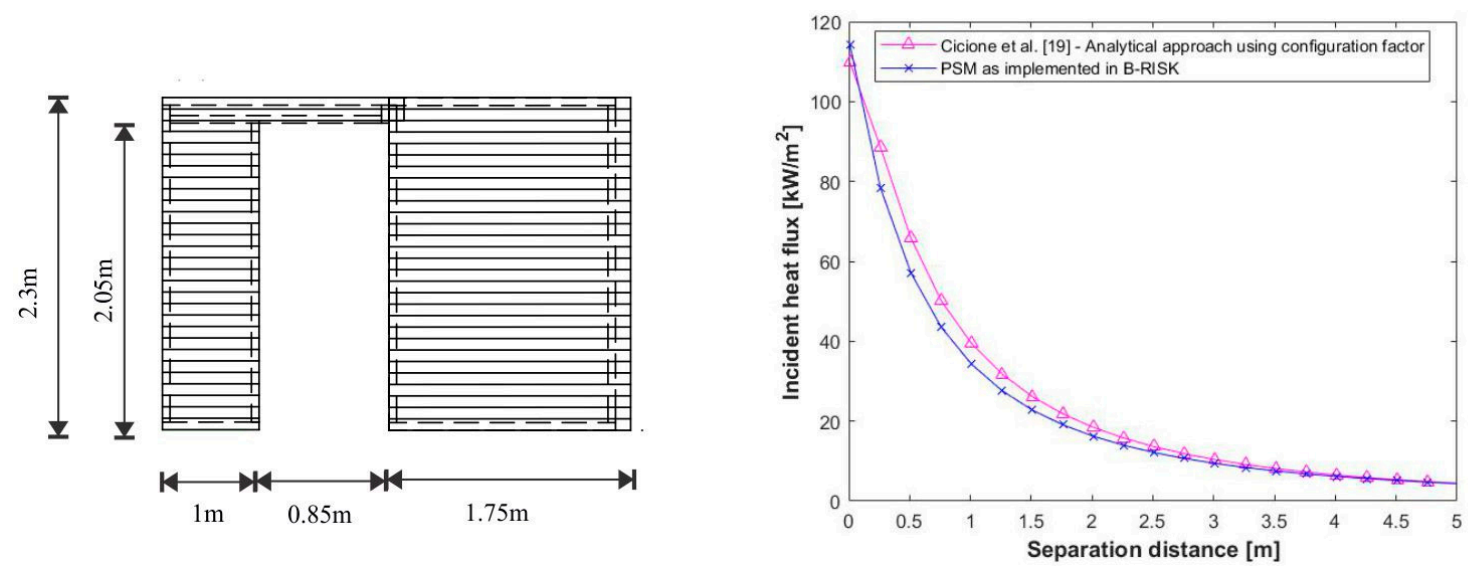

Figure 5. Comparison of the radiation emitted from an informal settlement dwelling (ISD) as calculated using the PSM and Equation (5) (refer to Reference [19] for more details on the analytical method).

It should, however, be noted that should Equation (5) be applied to a wall scenario with no openings, the radiation emitted would be significantly less compared to the PSM (the radiation versus distance would remain the same for the PSM), but since the fire spread is assumed to occur at the point where the radiation is the highest, the PSM is sufficient for the intended use in this paper.

\subsection{Ignition}

Currently, B-RISK employs the Flux-Time Product (FTP) method as its default ignition submodel. The FTP method is a simplified approach to estimate the time-to-ignition of a combustible item subjected to an incident heat flux. Shields et al. [21] generalized the FTP method such that

$$
F T P=t_{i g}\left(\dot{q}_{f}^{\prime \prime}-\dot{q}_{c r}^{\prime \prime}\right)^{n}
$$

where $t_{i g}$ is the time-to-ignition (s); $\dot{q}_{f}^{\prime \prime}$ is the incident heat flux emitted by the burning item; $\dot{q}_{c r}^{\prime \prime}$ is the critical heat flux of the target item $\left(\mathrm{kW} / \mathrm{m}^{2}\right)$; and $n$ is known as the FTP index. The values for $F T P, n$ and $\dot{q}_{c r}^{\prime \prime}$ are determined by conducting a number of ignition experiments, at different incident heat fluxes, and plotting the range of $1 / t_{i g}{ }^{1 / n}$ values against the corresponding incident heat fluxes, and iteratively varying $n$ to obtain the trendline with the highest correlation coefficient $\left(R^{2}\right)$, where the gradient of the trendline is equal to $F T P^{1 / n}$ and the point of intersection with the y-axis is equal to $\dot{q}_{c r}^{\prime \prime}$.

Piloted ignition measurements from the cone calorimeter for a variety of common lining and cladding materials used in informal settlements are available in References [22,23]. In this case, piloted ignition is assumed since ISDs are typically closely spaced [24,25] (especially the many dense settlements in Cape Town, and the experiments considered in this paper, although this is not always the case), so ignition is often assumed to be by means of flame impingement [9]. Assuming piloted ignition also accounts for the effects of wind tilting flames and causing channelling between the ISDs. Using Equation (6) and the cone calorimeter data, Figure 6 has been constructed where the FTP, $n$ and $\dot{q}_{c r}^{\prime \prime}$ values for a number of these common lining and cladding materials used in informal settlements have been obtained, and are presented in Table 1.

It should be noted that the FTP values, FTP indexes and the critical heat flux (CHF) values obtained in Table 1 are based on data from piloted cone calorimeter experiments. Hence, these values are only applicable for piloted ignition scenarios, as assumed in this paper, and does not hold true for cases where a piloted source is not present. Baker et al. [26] developed an empirical approximation that 
can be used to update the FTP index, FTP value and the CHF for auto-ignition scenarios, where they assumed that the time-to-ignition for the piloted- and auto-ignition modes will converge at an incident flux of $\dot{q}_{f}^{\prime \prime}=120 \mathrm{~kW} / \mathrm{m}^{2}$.

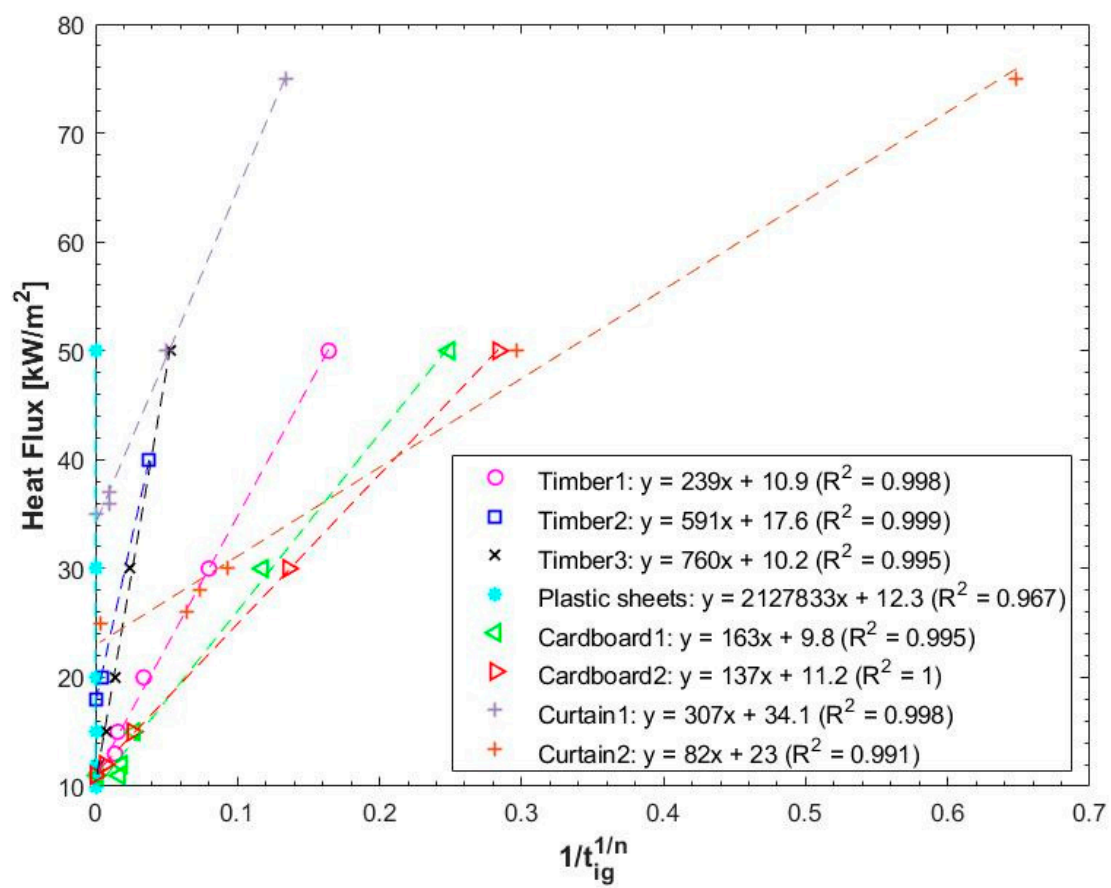

Figure 6. Correlation of ignition times and incident heat flux. $t_{i g}$ is the time-to-ignition in seconds (cone calorimeter data from Reference [23]).

Table 1. FTP, $n$ and $\dot{\boldsymbol{q}}_{c r}^{\prime \prime}$ values for a number of the common lining and cladding materials used in informal settlements.

\begin{tabular}{|c|c|c|c|}
\hline Item & FTP Value $\left(\mathrm{kW} / \mathrm{m}^{2}\right)^{\mathrm{n}}$ & FTP Index $\left({ }^{\mathrm{n}}\right)$ & Critical Heat Flux $\left(\dot{q}_{c r}{ }^{\prime \prime}\right)$ in $\mathrm{kW} / \mathrm{m}^{2}$ \\
\hline Timber 1 & 6394.5 & 1.6 & 10.9 \\
\hline Timber 2 & 2116.9 & 1.2 & 17.6 \\
\hline Timber 3 & 2866.0 & 1.2 & 10.2 \\
\hline Plastic sheets & 18.4 & 0.2 & 12.3 \\
\hline Cardboard 1 & 1251.7 & 1.4 & 9.8 \\
\hline Cardboard 2 & 224.5 & 1.1 & 11.2 \\
\hline Curtain 1 & 97.6 & 0.8 & 34 \\
\hline Curtain 2 & 1145.5 & 1.6 & 23 \\
\hline
\end{tabular}

\section{Twenty-Dwelling Experiment Versus B-RISK}

In this section, the B-RISK ISD fire spread method proposed by Reference [10] is benchmarked against a full-scale 20-dwelling experiment [8]. A parametric study of the effect of (a) wind speed, (b) wind direction, and (c) ignition criteria on the fire spread rates is then conducted by only changing one variable of the 20-dwelling benchmarked simulation (baseline simulation) and comparing it to the baseline simulation and the other baseline variants.

\subsection{Experimental and Numerical Model Setup}

At the end of 2018, Stellenbosch University and the University of Edinburgh conducted the world's largest informal settlement dwelling fire experiment to date in Worcester, South Africa [8]. 
The experiment consisted of 20 dwellings, with all dwellings having a floor area of $3.6 \mathrm{~m} \times 2.4 \mathrm{~m}$ and a height of $2.2 \mathrm{~m}$. All dwellings were lined with corrugated cardboard and had six timber cribs each, giving an approximate fuel load of $24 \mathrm{~kg} / \mathrm{m}^{2}$ per dwelling. Each crib consisted of $280.48 \mathrm{~m} \times 0.48 \mathrm{~m} \times 1 \mathrm{~m}$ timber pieces, stacked as seven alternating layers of four lengths. The experimental setup along with the details of the 20-dwelling burn experiment needed for this paper is depicted in Figure 7. For more information about the 20-dwelling burn experiment, the reader should refer to [8], with a video of the experiment presented at: https://youtu.be/kkXr6ueakAU. The fire was started simultaneously in dwellings A1-A4 and was left to spread from the left of Figure 7 to the right. "Timber" or "Sheeting" in the figure legend imply that the dwelling was clad with timber planks or corrugated steel sheeting, respectively. The wind blew at approximately $20 \mathrm{~km} / \mathrm{h}(5.6 \mathrm{~m} / \mathrm{s})$ from a west-northwesterly direction, depicted in Figure 7.

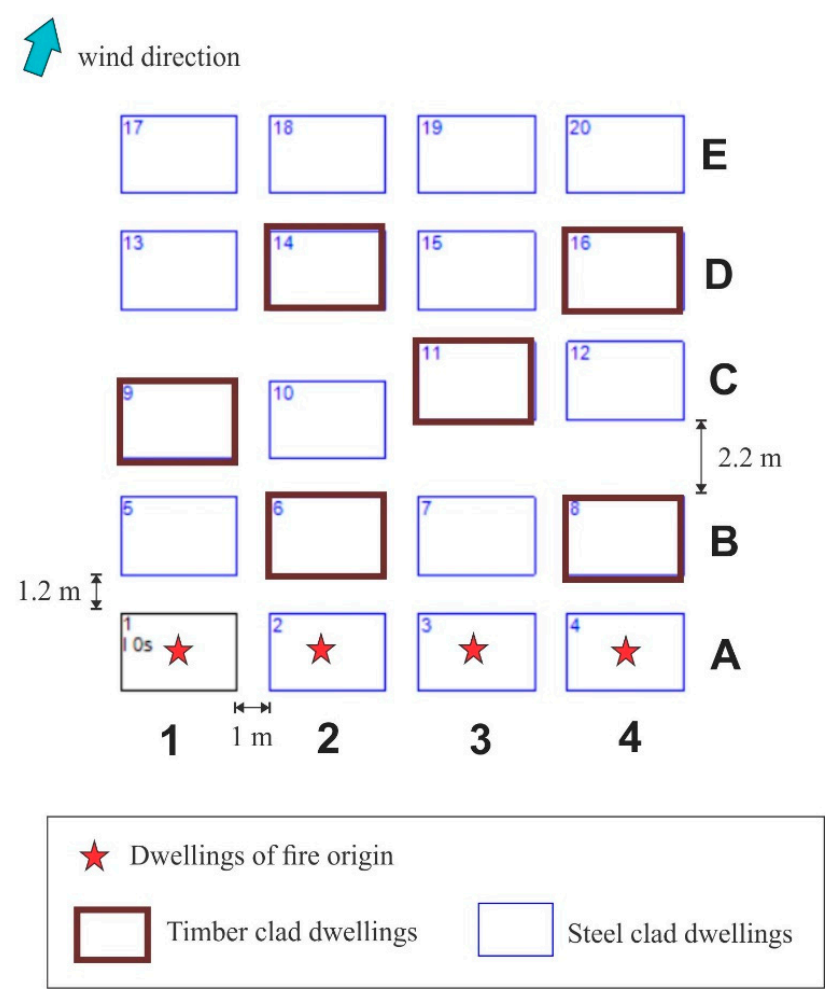

Figure 7. Layout of the 20-dwelling fire experiment [8].

The geometric setup of the B-RISK 20-dwelling simulation is depicted in Figure 8. For dwellings 1-4 (i.e., A1-A4 in Figure 7), all ignition criteria (FTP, $\mathrm{n}$ and CHF) were set to 0 to ensure that the dwellings ignite simultaneously as soon as the simulation started. For the remaining dwellings, the ignition criteria of Cardboard 2 (i.e., the cardboard used for internal lining in the 20-dwelling experiment), as listed in Table 1, were used. For the simulations that follow, it is postulated that, for timber clad dwellings, the cardboard lining ignites before the timber cladding (i.e., since the cardboard has lower CHF, FTP values and FTP index values compared to the timber, and since both the cardboard and timber are exposed to the same incident heat flux). Observations from the three timber-clad dwellings experiment [9], with similar configurations as used here, highlighted this phenomenon where the cardboard ignited, experienced rapid fire spread across its surface inside the dwelling, and was the primary cause of flashover.

Using the crib model discussed by Babrauskas [27], it was determined that the crib mass loss rate in these dwellings were most likely fuel surface area-controlled. Using the heat of combustion as $16.8 \mathrm{MJ} / \mathrm{kg}$ [8], and assuming the structures collapse approximately $7.1 \mathrm{~min}$ after the maximum heat release rate (HRR) is reached [28] (based on an averaged value from multiple experiments), the HRR 
curve depicted in Figure 9 is obtained. Although the dwellings clad with timber planks will have a higher HRR (since the timber planks will contribute to the total fuel load and the total HRR), the initial growth period of timber clad dwellings are assumed to be unaffected by the timber planks (controlled by the cribs), and since the timber planks are thin (12 mm thick), it is assumed that it will burn away rapidly after the planks start burning [6,7]. Hence, for simplicity, it was decided to assign the HRR curve depicted in Figure 9 to all dwellings for the baseline simulation. However, to investigate the sensitivity of the HRR curve of the timber dwellings, three parametric simulations were run, as discussed below. The HRR values in the curve depicted in Figure 9 were increased by 20\%,50\% and 100\% (i.e., the fuel load contribution of the timber planks was used to increase the area under the HRR curve [7]), respectively. It was found that when the timber dwellings had HRR values $50 \%$ greater than the steel dwellings (Figure 9), the predicted spread rates are closer to the experimental spread rates, as depicted in Figure 10.

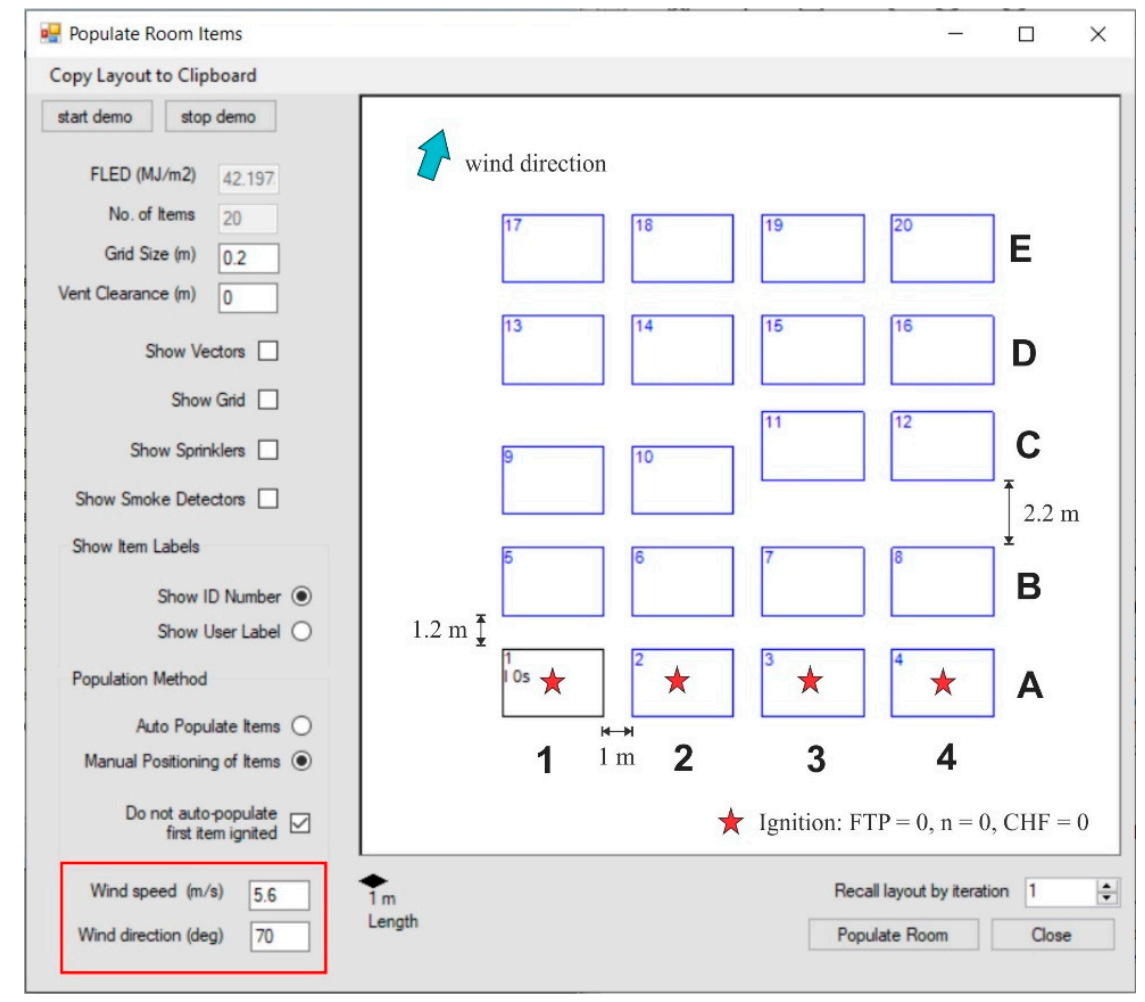

Figure 8. Annotated room (fully open to "outside") setup in B-RISK, where ISDs A1-A4, B1-B4, C1-C4, D1-D4 and E1-E4 are modelled as items. Wind direction used in the B-RISK setup was 70 degrees and a wind speed of $5.6 \mathrm{~m} / \mathrm{s}$.

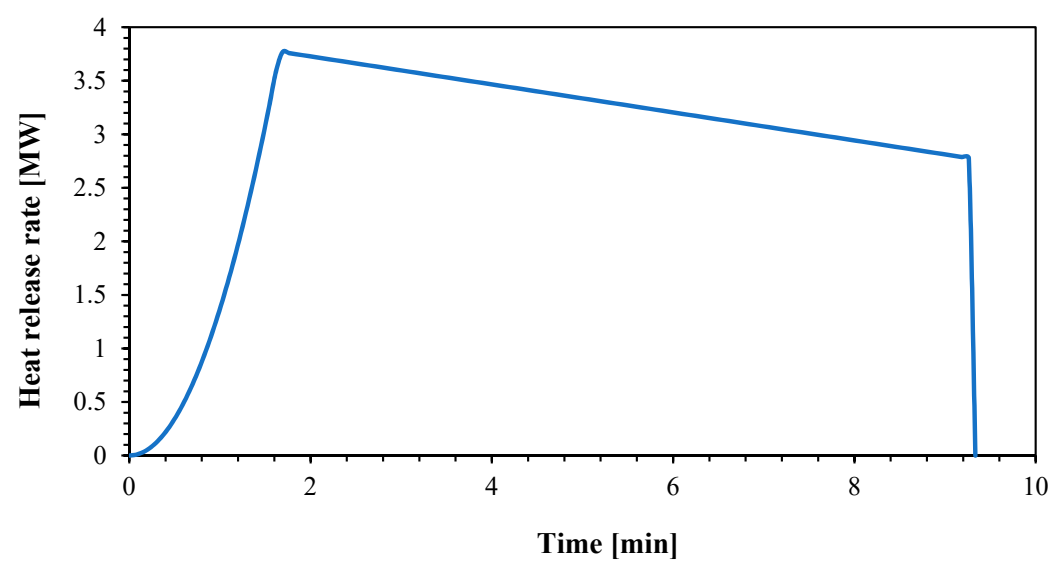

Figure 9. Baseline heat release rate curve for the dwellings used in the 20-dwelling experiment. 

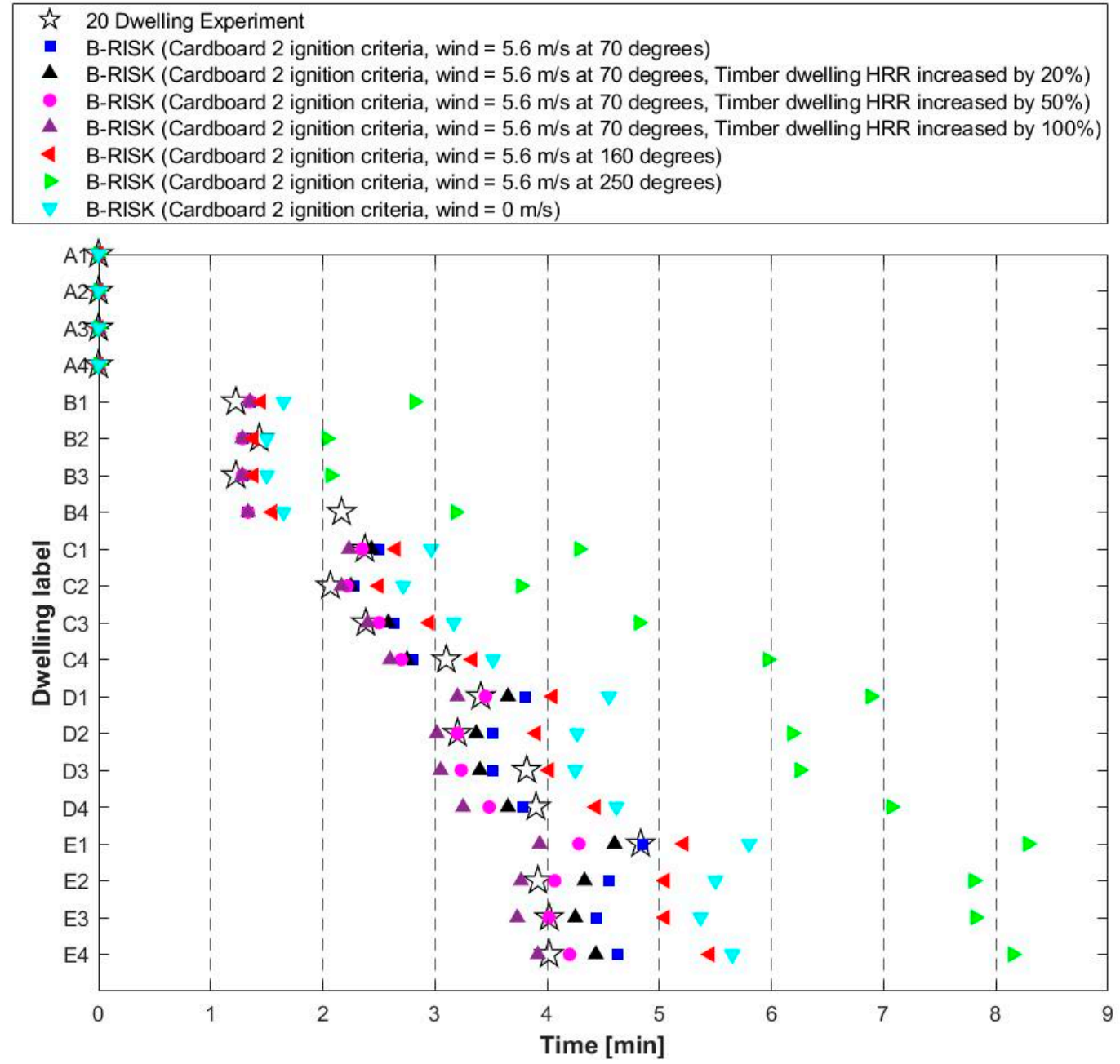

Figure 10. Experimental and simulation time-to-ignition results for the different configurations.

The maximum transient HRR of the timber used is around $200 \mathrm{~kW} / \mathrm{m}^{2}$, with a stable HRR of $100-150 \mathrm{~kW} / \mathrm{m}^{2}$, as determined by a cone calorimeter [23]. If this value is multiplied by the surface area of the timber cladding, the maximum HRR increases by approximately 2.3-4.6 MW for each side of the wall. However, due to ventilation control inside an ISD, and air not being able to reach dwellings within the settlement due to combustion occurring in the surrounding dwellings, the full HRR of the combined fuel plus cladding will not be reached. If it is assumed that only the outside of an ISD contributes to the increased HRR at an average of $100 \mathrm{~kW} / \mathrm{m}^{2}$ (lower bound used since not all of the surface area may burn at the same time and given the lack of free-flow air between the ISDs within the settlement), then this gives an increased HRR of $60 \%$, although an increase in the HRR of $100 \%$ would be conceivable.

A soot yield of $0.015 \mathrm{~g} / \mathrm{g}, \mathrm{CO}_{2}$ of $1.33 \mathrm{~g} / \mathrm{g}$ and radiant loss fraction $\chi_{R}$ of 0.3 were taken from Table 3-4.14 of the SFPE Handbook [20]. The heat of gasification $(1.8 \mathrm{~kJ} / \mathrm{g})$ was selected from Table 3-4.7 of the SFPE Handbook [20] to represent the overall average fuel load, based on similar representative materials. It should be noted that, since this work only makes use of the radiation and ignition submodels, the exact values of the parameters specified above are not critical (i.e., they are not used in the submodels, except for the radiant loss fraction), but the B-RISK requires values to be specified.

\subsection{Experimental versus Numerical Results}

The results of the 20-dwelling experiment and B-RISK simulations are depicted in Figure 10. For the baseline simulation (Cardboard 2 ignition criteria, wind $=5.6 \mathrm{~m} / \mathrm{s}$ at 70 degrees), where the wind 
conditions are the same as the experiment, B-RISK shows a good correlation with the 20-dwelling experiment. The time-to-ignition of the dwellings in Rows A to D have negligible variation between the simulation and experiment, with only Row E showing slightly slower times-to-ignition (30-40 s slower) compared to the experimental times. This could be as a result of the timber cladding contributing to the HRR not being accounted for in the baseline simulation, which is evident when considering the simulation where the items that represent the timber dwellings were assigned an increased HRR of $50 \%$.

For interest, some variations in the baseline simulation (Cardboard 2 ignition criteria, wind $=5.6 \mathrm{~m} / \mathrm{s}$ at 70 degrees) were run to see the effect of the wind direction and wind speed on the fire spread rates. Changing the wind direction by 90 degrees (Cardboard 2 ignition criteria, wind $=5.6 \mathrm{~m} / \mathrm{s}$ at 180 degrees) does slightly decrease the time-to-ignition of the 20 dwellings compared to the baseline simulation (by under a minute for Row E). For the simulation with no wind and wind in the opposite direction, the time-to-ignition increased significantly (over $3 \mathrm{~min}$ for Row E) compared to the baseline simulation, with the wind direction in the opposite direction having the greatest effect on increasing the ignition time as one would expect. Changing the wind direction by 180 degrees (i.e., in the opposite direction as the fire spread) significantly reduces the likelihood of piloted ignition, meaning that the assumption (i.e., the ignition criteria set is based on the assumption of piloted ignition) made in this case would not be correct. This means that the time-to-ignition values depicted in Figure 10 are likely overpredicted (i.e., the time-to-ignition values would be much larger, or ignition might not have occurred, if auto-ignition values were assumed). For the no wind condition, it may initially be assumed that all dwellings in Row B should ignite simultaneously due to them being equidistant to their corresponding neighbour in Row A; however, it can be seen in Figure 10 that this is not the case. If the radiation sources (dwellings in Row A) are considered, it is clear that dwellings B2 and B3 would receive radiation from three dwellings in Row $\mathrm{A}$, whereas dwellings $\mathrm{B} 1$ and $\mathrm{B} 4$ on the edges of the experiment receive radiation from just two dwellings in Row A.

\subsection{Effect of Ignition Criteria}

It is well known that ISDs are constructed from a variety of materials [29], and that no two dwellings are the same. The material used does not only vary from dwelling to dwelling, but also from settlement to settlement. As mentioned above, the original semi-probabilistic approach [10] demonstrated the predictive capabilities of the software against a real informal settlement fire, but found that the simulation overpredicted the spread rates. It was postulated that this was the result of a) human intervention in the early stages of the fire, and b) the use of only one set of ignition criteria (i.e., the ignition criteria of cardboard) for all dwellings. Hence, to investigate the effect of the ignition criteria of the different combustibles listed in Table 1, a simulation for each set of ignition criteria has been run and compared to the original (Cardboard 2 ignition criteria, wind $=5.6 \mathrm{~m} / \mathrm{s}$ at 70 degrees) dwelling simulation, as depicted in Figure 11.

Figure 11 clearly shows that the ignition criteria of the items play an important role in the spread rates predicted. In this case, the time it took for all 20 dwellings to ignite can change by as much as $3.6 \mathrm{~min}$, i.e., $4 \mathrm{~min}$ for Plastic sheets to $7.6 \mathrm{~min}$ for Timber 2, which is a $90 \%$ increase in the time to ignition. Comparing the spread rates of Curtain 1 and Curtain 2, it seems that the CHF has a greater effect on the fire spread rates compared to FTP and $n$. Since both the FTP value and the FTP index are higher for Curtain 2, one would expect the spread rate to be lower (slower spread), not higher (faster spread). Thus, since the spread rate of Curtain 2 is higher, it implies that the difference is as a result of the lower CHF (i.e., $34 \mathrm{~kW} / \mathrm{m}^{2}$ for Curtain 1 versus $23 \mathrm{~kW} / \mathrm{m}^{2}$ for Curtain 2). 


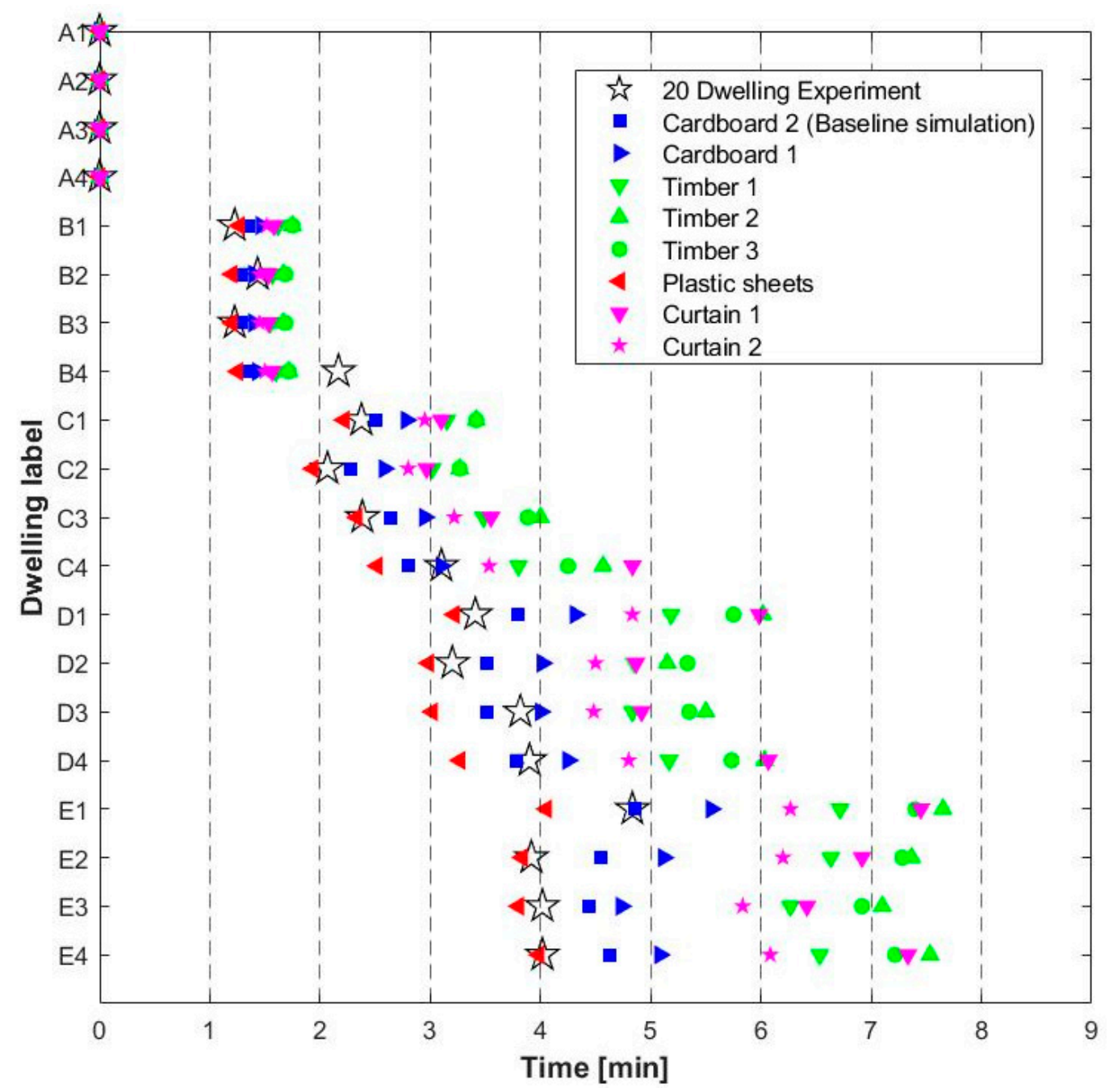

Figure 11. Effect of the B-RISK simulation ignition criteria on the time-to-ignition.

\subsection{Colour Maps to Investigate Informal Settlement Layout Configurations}

In order to create a tool that can help government, local authorities and decision makers to simulate fires to quantify the magnitude of an incident to which they may need to respond, to identify high risk settlements, or to identify high risk areas within a settlement, the output of such a tool needs to be understandable in a relatively non-technical manner. In the future, it would be advantageous to produce colour maps, showing the potential fire spread rates and patterns of all informal settlements, e.g., in Cape Town, for a prevailing wind direction. The colour maps would highlight the settlements most at risk of large conflagrations and would identify "hot spots" within specific settlements. A visual depiction of the fire spread rates would also help with evaluating the effectiveness of re-blocking and firebreak strategies. Re-blocking refers to the collaborative reorganisation of home layouts in an area to provide a more efficient and structured community pattern, and is typically assisted by a municipal agency or another organisation (e.g., non-governmental organizations (NGO)).

Fire spread data can be graphically displayed in many ways as there are instantaneous and averaged area spread rates $\left(\mathrm{m}^{2} / \mathrm{h}\right)$, instantaneous and averaged linear spread rates $(\mathrm{m} / \mathrm{h})$, heat-release rate changes with time, and other such metrics. A simplified representation of the fire behaviour is presented below by plotting what is called a fire line linear progression rate $(\mathrm{m} / \mathrm{h})$, which is taken relative to the start of the simulation. Hence, the value is found by calculating the linear position of the fire line over the total time since time zero. The advantage of this metric is that it implicitly considers the time history of the fire behaviour. For example, if a fire has to cross a larger open 
distance, which slows it down, all values on the far side of the open distance will be influenced by the delay. In addition, other metrics, such as the instantaneous spread rates, are useful to see localised phenomena, but are not plotted in this paper due to space constraints.

As an illustration of the linear fire line progression rate, a colour map of the followings scenarios are depicted in Figures 12-15: (a) the 20-dwelling experiment (Figure 12a) and the baseline simulation (Figure 12b); (b) the baseline simulation, but where only dwelling A1 is ignited to see how it affects the spread rates and the spread pattern; (c) the baseline simulation, where only dwelling A1 is ignited, with a $3.5 \mathrm{~m}$ firebreak between Columns 2 and 3; and (d) the baseline simulation, where only dwelling $\mathrm{A} 1$ is ignited, with a $4.5 \mathrm{~m}$ firebreak between Columns 2 and 3 . Note that for all cases the wind direction and wind speed were kept the same as the baseline case.
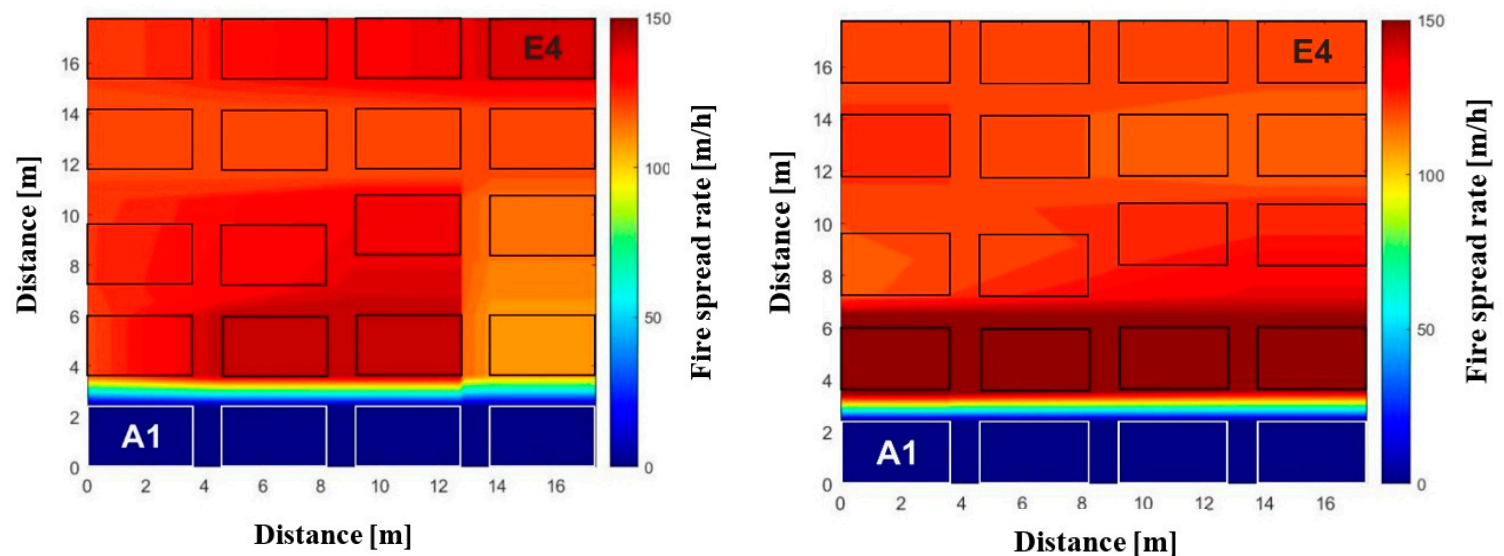

Figure 12. (a) Colour map depicting the fire line progression rate relative to time zero, and the pattern of the 20-dwelling experiment, where dwellings A1 to A4 are ignited. (b) Colour map depicting the fire line progression rate relative to time zero, and the pattern of the baseline simulations, where dwellings A1 to A4 are ignited.

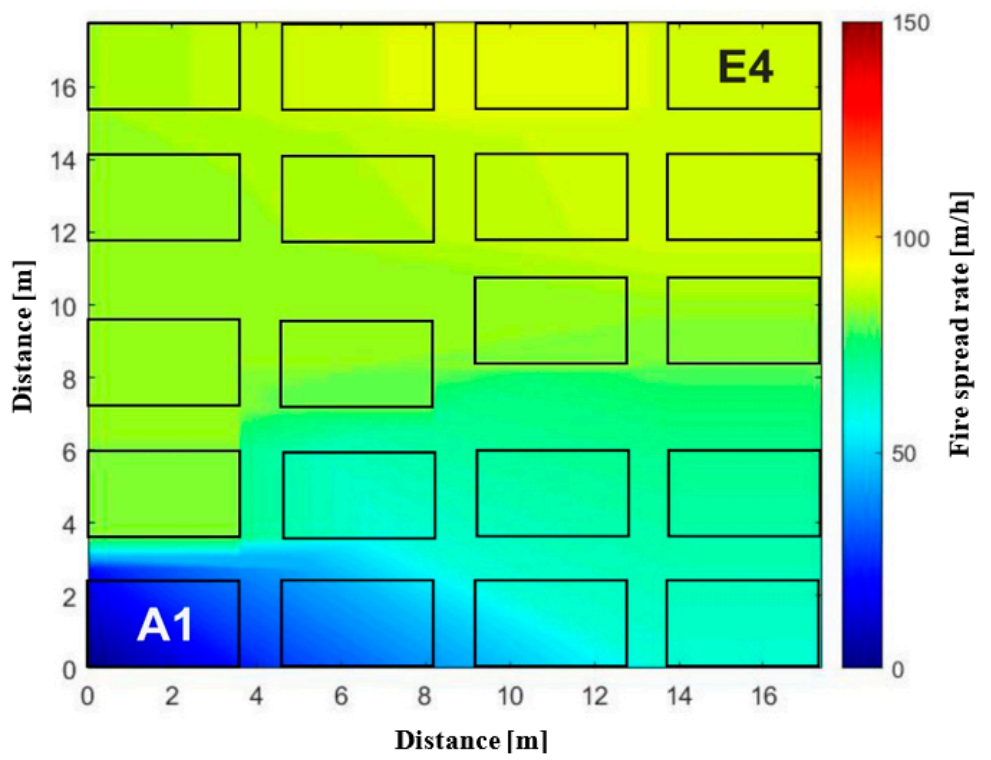

Figure 13. Colour map depicting the fire line progression rate relative to time zero, and the pattern of the baseline simulation, where only dwelling A1 is ignited. 


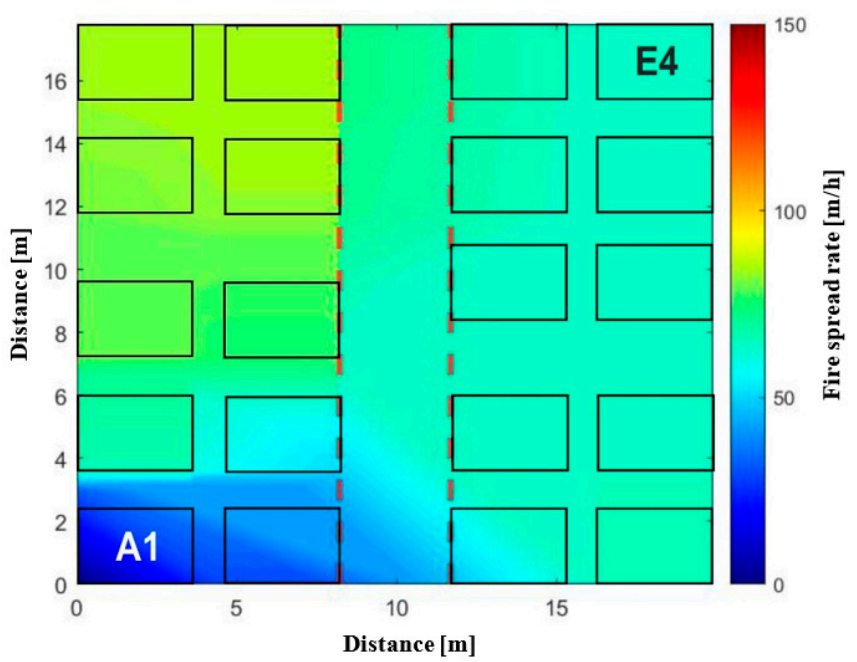

Figure 14. Colour map depicting the fire line progression rate relative to time zero and pattern of the baseline simulation, where only dwelling A1 is ignited with the $3.5 \mathrm{~m}$ fire break marked by dotted red lines.

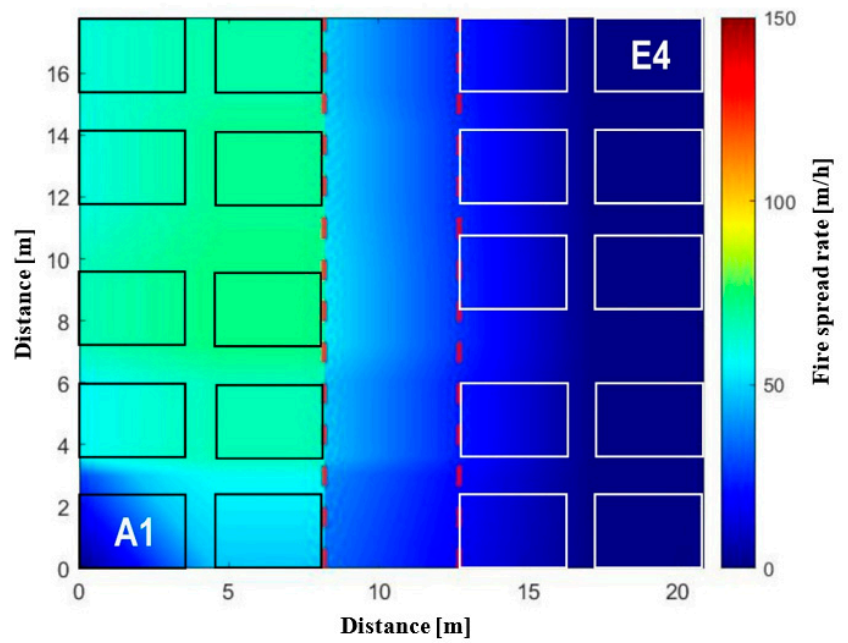

Figure 15. Colour map depicting the fire line progression rate relative to time zero and pattern of the baseline simulation, where only dwelling A1 is ignited with the $4.5 \mathrm{~m}$ fire break marked by dotted red lines.

As stated above, the fire line progression rates $(\mathrm{m} / \mathrm{h}$ ) are calculated by dividing the equivalent radius of the burn scar at that particular time by the time-to-ignition (from the start of the simulation). For example,

$$
S p_{i}=r_{i} / t_{i g-i}
$$

where $S p_{i}$ is the spread rate $(\mathrm{m} / \mathrm{h})$ at index $i$; $t_{i g_{i} i}$ is the B-RISK time-to-ignition of dwelling $i$; and $r_{i}$ is calculated as

$$
r_{i}=\sqrt{\left.i \times L \times W \times(i / 20)\left(C_{f}\right) / \pi\right)}
$$

where $L$ is the length of the dwelling ( $3.6 \mathrm{~m}$ in this case); $W$ is the width of the dwelling ( $2.4 \mathrm{~m}$ in this case); and $(i / 20)\left(C_{f}\right)$ is a "correction" factor to account for the spacings between the dwellings (since the area of these spacings are not explicitly calculated here), where 20 is the number of dwellings and $C_{f}$ is the total area (i.e., the area that encapsulate all the dwellings) divided by the sum of the area of all the dwellings. This is done for all items and the calculated fire line progression rate of an item is assigned to the four corners of the dwelling under consideration. The $\mathrm{x}$ and $\mathrm{y}$ axes of the colour maps are the Cartesian coordinates of the domain (the room) in the plan, where the bottom left corner is $(0,0)$ of the domain and it is the bottom left corner of dwelling A1 (Figure 8). 
Considering Figures 12-15, the proposed colour map output appears to be producing realistic results. Comparing Figure 12a,b to Figure 13, a decrease in the maximum spread rate of approximately $47 \%$ is observed. This is expected since igniting four dwellings simultaneously (Figure 12a,b) would generate a significantly greater combined HRR initially than a single dwelling (Figure 13), which would ultimately lead to a faster fire spread. For the case where four dwellings are ignited simultaneously, there are also more ISDs on fire in close proximity to others to ignite. Firebreaks are known to stop or reduce fire spread, and this is also reflected in the colour maps produced (Figures 14 and 15). A number of studies have investigated the critical separation distance needed between ISDs for fire spread not to occur. Cicione et al. [9] found that for "still" wind conditions, a distance of $3.8 \mathrm{~m}$ between ISDs is needed for fire spread not to occur. This distance was calculated by fitting an exponential function of the heat flux emitted versus distance from the dwelling to the experimental results. Based on this curve, it was found that at approximately $3.8 \mathrm{~m}$ the heat flux emitted by a single dwelling would be less than the critical heat flux of cardboard. This distance, however, neither accounts for wind effects nor for the effect of multiple dwellings burning and emitting energy simultaneously. Cicione et al. [7] used predictions from Fire Dynamics Simulator to determine that, based on model uncertainties, there is a probability of $6 \%$ (i.e., using the method proposed in the "Calculating model uncertainty" section of the FDS validation guide [30]) that the heat flux (predicted by the FDS simulations) received at $3 \mathrm{~m}$ away from a single ISD would exceed the assumed CHF of cardboard. Once again, the study did not consider wind, nor did it consider the effect of multiple dwellings burning and emitting energy at the same time. Wang et al. [31] also found that for "still" wind conditions, a distance of $3 \mathrm{~m}$ between ISDs is needed for fire spread not to occur. Considering Figure 14, it can clearly be seen that, although a $3.5 \mathrm{~m}$ separation (i.e., the fire break) did reduce the fire spread rate compared to the no firebreak case as depicted in Figure 14, the fire was still able to spread between Columns 2 and 3 (Figure 7). However, it should be noted that piloted ignition has been assumed in the ignition submodel, but with a $3.5 \mathrm{~m}$ separation between dwellings it is less likely that flame impingement will occur. On the other hand, increasing the fire break from $3.5 \mathrm{~m}$ to $4.5 \mathrm{~m}$, we see that fire spread does not occur and that the fire is contained to only one half of the mock settlement. Running the simulation for different separation distances, the minimum distance at which fire spread did not occur was $4.2 \mathrm{~m}$. Thus, these B-RISK simulations indicate that when the effects of wind and multiple dwellings burning at the same time are accounted for, a separation distance of $3.5 \mathrm{~m}$ is not sufficient, but rather a distance of at least $4.2 \mathrm{~m}$ is needed. It is, however, acknowledged that such a large separation distance is not always possible in reality as a result of socio-economic issues and insufficient spatial planning. Additionally, it should be noted that for higher wind speeds and different wind directions, this critical distance might change; however, these factors could be captured by using simulation tools such as B-RISK. Also, branding was not accounted for in this work, which could also significantly affect the critical separation distance.

The colour maps illustrate the first step towards producing risk maps for informal settlements using B-RISK, which may be a useful tool for fire brigades and local municipalities. In an ideal version of the software, the user would be able to import settlement geometry from a GIS file and run limitless iterations, by (1) randomly choosing a dwelling to ignite, (2) randomly allocating ignition criteria for each dwelling and (3) randomly assigning an HRR for each dwelling. The software would be able to consider varying wind conditions and produce an averaged colour map. This would highlight dwellings most at risk within a certain settlement, either regardless of the wind conditions or for particular wind conditions. In this paper, a number of simplifications were made to calculate the fire line progression rates used to generate the colour maps and should not be considered as "real" values. The purpose of these colour maps is to illustrate the possibilities of this work and to show the potential benefits of expanding the B-RISK capabilities to produce these colour maps.

\section{Spatial Metrics}

Gibson et al. [11] and Gibson et al. [32] first investigated various spatial metrics with respect to fire spread in informal settlements in Cape Town. Gibson et al. [32] report that, when using dwelling 
footprints mapped from LiDAR data, density (defined as the total dwelling footprint as a percentage of the settlement area) and edge density (defined by the sum of all dwellings' perimeters per hectare) can be used to identify settlements at risk of fire spread. Gibson et al. [11] found that the settlement average of the distance to a dwelling's first nearest neighbour, together with the standard deviation, can be used to identify settlements at risk of fire spread. A relationship to edge density was also found. That study also used the distance to a dwelling's first and third nearest neighbour to identify particular dwellings within a settlement most at risk of fire spread. It should be noted that in this work a single dwelling is defined as a structure with a single roof, or where roofs touch each other and therefore individual structures cannot reliably be distinguished. However, in many instances a dwelling may be subdivided internally and have multiple families or rooms within it, but this is very difficult to identify from the aerial photography from which the roofs were digitised [33].

In this paper, the average distance $(\mathrm{m})$ from a dwelling to its first through to fifth nearest neighbour (NN1 ... NN5), edge density ( $\mathrm{m} / \mathrm{ha}$ ) and density $(\%)$ were calculated for each new layout generated in B-RISK. Figure 16 illustrates an example of a settlement layout with Table 2 demonstrating how the spatial metrics are calculated. It should be noted that dwellings that adjoin are, for the purposes of the spatial metrics calculation, assumed to be a single dwelling. Some spatial metrics, such as density, require a confining area for which the spatial metric should be calculated. Gibson et al. [11] proposed a method where dwellings that fall within the potential fire spread separation distance of each other are included in the same "potential fire area" (PFA). In this paper, the critical separation distance determined through the modelling was used. Dwellings are firstly buffered (see Figure 16) using half the critical separation distance. Buffering refers to a reclassification/adjusting of the area under investigation, based on offsetting the perimeter by a specific amount. Firstly, any dwelling within the separation distance of each other are joined in the same buffered area, i.e., a polygon outlining the area considered. Secondly, the resulting polygon is then buffered back by half the separation distance so that the border of the PFA aligns with outermost walls of the outermost dwellings, and the outermost dwellings are connected by the outline of the buffer. This technique is a useful tool for creating a polygon around a number of individual homes that could burn in a single fire, and ignoring adjacent homes to which the fire would not spread.

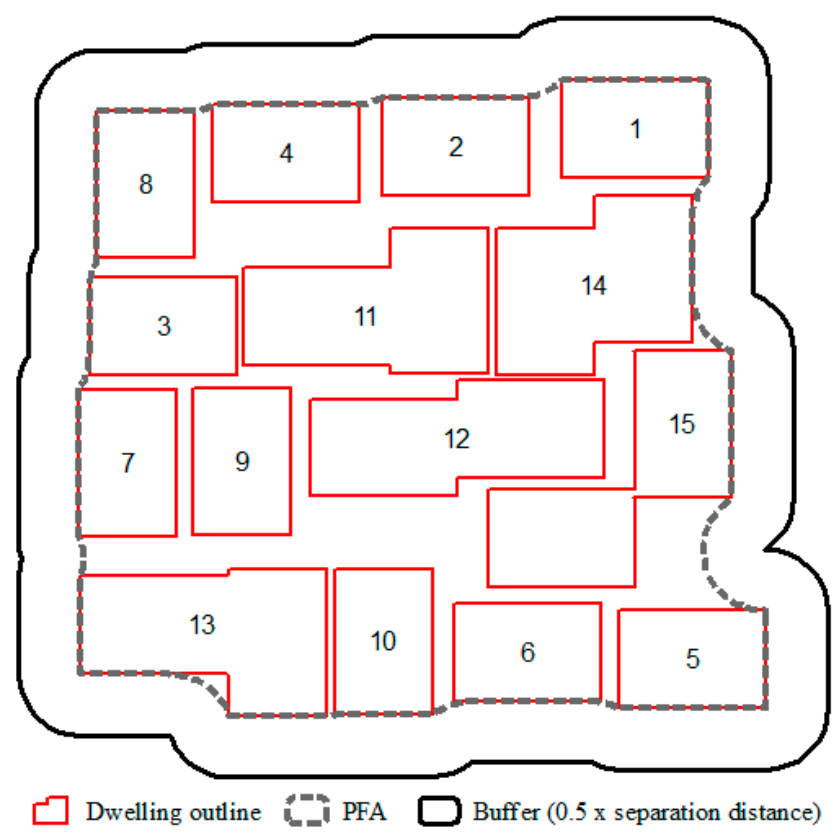

Figure 16. Example settlement, demonstrating the construction of the potential fire area (PFA). Dwellings are buffered outwards by $0.5 \times$ the separation distance. The resulting polygon is then buffered back by the same distance to obtain the PFA aligning with the walls of the outermost dwellings. Numbers in each dwelling correspond to the ID in Table 2. 
Table 2. Spatial metrics calculated for the settlement shown in Figure 16.

\begin{tabular}{|c|c|c|c|c|c|c|c|}
\hline ID & $\begin{array}{l}\text { Perimeter } \\
(\mathrm{m})\end{array}$ & Area $\left(m^{2}\right)$ & $\begin{array}{l}\text { NN1:ID } \\
\text { Distance } \\
\text { (m) }\end{array}$ & $\begin{array}{l}\text { NN2:ID } \\
\text { Distance } \\
\text { (m) }\end{array}$ & $\begin{array}{l}\text { NN3:ID } \\
\text { Distance } \\
\quad(\mathrm{m})\end{array}$ & $\begin{array}{l}\text { NN4:ID } \\
\text { Distance } \\
\text { (m) }\end{array}$ & $\begin{array}{l}\text { NN5:ID } \\
\text { Distance } \\
\quad(\mathrm{m})\end{array}$ \\
\hline 1 & 12 & 8.64 & $\begin{array}{c}14 \\
0.45\end{array}$ & $\begin{array}{c}2 \\
0.80\end{array}$ & $\begin{array}{c}11 \\
2.16\end{array}$ & $\begin{array}{c}15 \\
4.27\end{array}$ & $\begin{array}{c}4 \\
4.97\end{array}$ \\
\hline 2 & 12 & 8.64 & $\begin{array}{c}4 \\
0.60\end{array}$ & $\begin{array}{c}1 \\
0.80\end{array}$ & $\begin{array}{c}11 \\
0.80\end{array}$ & $\begin{array}{c}14 \\
0.82\end{array}$ & $\begin{array}{c}3 \\
4.10\end{array}$ \\
\hline 3 & 12 & 8.64 & $\begin{array}{c}11 \\
0.19\end{array}$ & $\begin{array}{c}9 \\
0.35\end{array}$ & $\begin{array}{c}7 \\
0.37\end{array}$ & $\begin{array}{c}8 \\
0.47\end{array}$ & $\begin{array}{c}4 \\
1.83\end{array}$ \\
\hline 4 & 12 & 8.64 & $\begin{array}{c}8 \\
0.42\end{array}$ & $\begin{array}{c}2 \\
0.57\end{array}$ & $\begin{array}{c}11 \\
1.00\end{array}$ & $\begin{array}{c}3 \\
1.83\end{array}$ & $\begin{array}{c}14 \\
3.44\end{array}$ \\
\hline 5 & 12 & 8.64 & $\begin{array}{c}6 \\
0.45\end{array}$ & $\begin{array}{c}15 \\
0.58\end{array}$ & $\begin{array}{c}12 \\
3.27\end{array}$ & $\begin{array}{c}10 \\
4.59\end{array}$ & $\begin{array}{c}14 \\
5.81\end{array}$ \\
\hline 6 & 12 & 8.64 & $\begin{array}{c}15 \\
0.40\end{array}$ & $\begin{array}{c}5 \\
0.44\end{array}$ & $\begin{array}{c}10 \\
0.55\end{array}$ & $\begin{array}{c}12 \\
2.62\end{array}$ & $\begin{array}{c}13 \\
3.15\end{array}$ \\
\hline 7 & 12 & 8.64 & $\begin{array}{c}3 \\
0.37\end{array}$ & $\begin{array}{c}9 \\
0.40\end{array}$ & $\begin{array}{c}13 \\
0.98\end{array}$ & $\begin{array}{c}11 \\
1.76\end{array}$ & $\begin{array}{c}8 \\
3.24\end{array}$ \\
\hline 8 & 12 & 8.64 & $\begin{array}{c}4 \\
0.42\end{array}$ & $\begin{array}{c}3 \\
0.47\end{array}$ & $\begin{array}{c}11 \\
1.23\end{array}$ & $\begin{array}{c}9 \\
3.22\end{array}$ & $\begin{array}{c}7 \\
3.24\end{array}$ \\
\hline 9 & 12 & 8.64 & $\begin{array}{c}3 \\
0.35\end{array}$ & $\begin{array}{c}7 \\
0.40\end{array}$ & $\begin{array}{c}12 \\
0.49\end{array}$ & $\begin{array}{c}11 \\
0.58\end{array}$ & $\begin{array}{c}12 \\
0.83\end{array}$ \\
\hline 10 & 12 & 8.64 & $\begin{array}{c}13 \\
0.20\end{array}$ & $\begin{array}{c}6 \\
0.55\end{array}$ & $\begin{array}{c}9 \\
1.34\end{array}$ & $\begin{array}{c}15 \\
1.37\end{array}$ & $\begin{array}{c}12 \\
1.77\end{array}$ \\
\hline 11 & 19.2 & 17.28 & $\begin{array}{c}12 \\
0.15\end{array}$ & $\begin{array}{c}14 \\
0.19\end{array}$ & $\begin{array}{c}3 \\
0.19\end{array}$ & $\begin{array}{c}9 \\
0.58\end{array}$ & $\begin{array}{c}2 \\
0.80\end{array}$ \\
\hline 12 & 20.1 & 17.28 & $\begin{array}{c}14 \\
0.13\end{array}$ & $\begin{array}{c}11 \\
0.15\end{array}$ & $\begin{array}{c}15 \\
0.27\end{array}$ & $\begin{array}{c}9 \\
0.49\end{array}$ & $\begin{array}{c}10 \\
1.77\end{array}$ \\
\hline 13 & 19.2 & 17.28 & $\begin{array}{c}10 \\
0.20\end{array}$ & $\begin{array}{c}9 \\
0.83\end{array}$ & $\begin{array}{c}7 \\
0.98\end{array}$ & $\begin{array}{c}12 \\
1.78\end{array}$ & $\begin{array}{c}6 \\
3.15\end{array}$ \\
\hline 14 & 18.4 & 17.28 & $\begin{array}{c}12 \\
0.13\end{array}$ & $\begin{array}{c}11 \\
0.19\end{array}$ & $\begin{array}{c}15 \\
0.22\end{array}$ & $\begin{array}{c}1 \\
0.49\end{array}$ & $\begin{array}{c}2 \\
0.82\end{array}$ \\
\hline 15 & 23.6 & 17.28 & $\begin{array}{c}14 \\
0.22\end{array}$ & $\begin{array}{c}12 \\
0.27\end{array}$ & $\begin{array}{c}6 \\
0.40\end{array}$ & $\begin{array}{c}5 \\
0.58\end{array}$ & $\begin{array}{c}10 \\
1.37\end{array}$ \\
\hline Sum & 220.5 & 172.8 & & & & & \\
\hline Average & & & 0.31 & 0.47 & 0.95 & 1.69 & 2.69 \\
\hline PFA & & 231.26 & & & & & \\
\hline Density (\%) & \multicolumn{3}{|c|}{$\begin{array}{c}=\text { Sum Area } / \text { PFA } \times 100 \\
=172.8 / 231.26 \times 100 \\
=74.7\end{array}$} & $\begin{array}{l}\text { Edge density } \\
\text { (m/ha) }\end{array}$ & \multicolumn{3}{|c|}{$\begin{array}{c}=\text { Sum Perimeter } / \text { PFA } \times 10,000 \\
=220.5 / 231.26 \times 10,000 \\
=9535\end{array}$} \\
\hline
\end{tabular}

Density and close proximity of dwellings has been stated as a cause for rapid fire spread in informal settlements [25]. By analysing the density of dwellings together with the average distance to nearest neighbours (NN1 ... NN5), a more nuanced understanding of the settlement layout and its impact on fire spread can be obtained. For example, if a settlement has a low average distance to NN1 but high average distance to NN2 ... NN5, it implies that fire will more likely spread from the ignited dwelling to NN1 in a stepwise manner, and the fire is more likely to spread in only single directions (i.e., since the distance to NN2 ... NN5 might be far enough for spread to those neighbours not to occur). However, if a low average distance to NN1 ... NN5 is discovered, the spread will be radial as an ignited dwelling will be able to spread to more neighbours more easily. Through analysing these spatial metrics together with the fire spread rates, it will become apparent which of these metrics are the most influential. For example, it may be that the density metric captures the information contained 
in the average distance to NN1 ... NN5, in which case, for future studies, distance to NN will not be required, streamlining the processing.

The importance of edge density has been raised here since dwellings are ignited and spread from their edges. The logic therefore follows that settlements with a high edge density (i.e., many longer, thinner homes) offer more opportunities for fire to spread than settlements with a low edge density. The two previous papers by Gibson et al., which investigated this, revealed some correlation and therefore the role of this spatial metric is further explored here to determine its importance.

\section{Identifying the Spatial Metrics That Are Indicative of a Higher Fire Spread Risk}

To determine which spatial metrics are the most influential for informal settlement fire spread, the radiation and ignition submodels of B-RISK are used (discussed in Section 3) to predict the fire spread rates for a variety of randomly populated "informal settlement" configurations. From these, the average spread rates (i.e., depending on which dwelling ignited first in the populated scenario) were obtained and the spatial metrics of the corresponding settlement scenario were calculated. In this case, 25 different settlement configurations, consisting of 20 dwellings each (which were the same as the baseline dwellings used in Section 3), were randomly populated (i.e., the location of the dwellings were randomly populated). Each settlement scenario thus had a different dwelling layout configuration, resulting in different spatial metrics values, an example of which can be seen in Figure 16 and Table 2 .

For each scenario, the average time to ignite all 20 dwellings has been determined, with each dwelling in the settlement configuration given a chance to ignite first. This resulted in 20 different times-to-ignition for the whole layout for the same scenario (a total of 500 calculated fire spread rates) from which the average time-to-ignition and the average spread rates are determined. To ensure that a variety of settlement densities were captured, 10 scenarios have a domain (i.e., the room floor area in B-RISK) of $17.5 \mathrm{~m} \times 17.5 \mathrm{~m}$ to simulate very dense settlements (70-79\% density), 10 scenarios have a domain of $18.3 \mathrm{~m} \times 18.8 \mathrm{~m}$ (same as the 20-dwelling experiment) to simulate slightly less dense settlements (56-67\%), and 5 scenarios have a domain of $20.5 \mathrm{~m} \times 20.5 \mathrm{~m}$ to simulate less dense settlements (57-61\%). Density refers to the percentage of area covered by dwellings and a comparison to densities found in reality is considered when the results are discussed below. Although burned areas of large fires have been found to have densities at or exceeding the density given in the "very dense settlement" scenario [11], less dense settlements have been simulated to capture a wider variety of spatial metrics beyond just density. It should be noted here that the dwelling locations for scenarios randomly populated in B-RISK are not automatically captured in an output file, nor is the time-to-ignition. Hence, for the 500 simulations done in this work, all B-RISK data has been captured manually, as well as all spatial metric data, and thus only 25 settlement scenarios have been simulated. The fire spread rates for the 25 scenarios ranged from $2090-2958 \mathrm{~m}^{2} / \mathrm{h}$. For future use, it would be advantageous to automate the process so that more simulations can be carried out.

Based on the analyses conducted, an interesting question arises-can a simplified analytical equation be developed to approximate fire spread based on measurable settlement metrics? Although it is not possible to include the factors discussed in the introduction (e.g., branding, suppression, fuels between homes, etc.), predictions still provide a useful benchmark and tool for comparing and quantifying risk. In ArcGIS 10.5, the dwellings for each scenario were digitised, the potential fire spread area (PFA) for each scenario was created and the spatial metrics for each PFA were calculated. These spatial metrics, together with the B-RISK average fire spread rates, were used to derive a linear equation (derived from the correlation between the dependent and independent variables) to predict the average fire spread rate of an informal settlement using only spatial metrics:

$$
S_{p}\left(x_{1}, x_{2}, \ldots x_{n}\right)=a x_{1}+b x_{2}+\ldots+z x_{n}+C
$$

where $S_{p}$ (the dependent variable) is the predicted potential average fire spread rate as a function of the settlement's spatial metrics $\left(\mathrm{m}^{2} / \mathrm{h}\right)$ and $x_{1}$ to $x_{n}$ (the independent variables, as defined below) are the 
spatial metrics. It should be noted that in the development of the equation, only spatial metrics from the simulated scenarios were used and these do not represent the full range of scenarios (and thus spatial metrics) that are found in reality. Thus, the application of the developed equations to PFAs with spatial metrics exceeding the range covered in the B-RISK scenarios are considered less reliable as this will be an extrapolation of the equation. The spatial metrics considered were density, edge density, average distance to NN1 ... NN5 as well as the additive metrics of NN1 and subsequent NNs, e.g., NN1+NN2, $\mathrm{NN} 1+\mathrm{NN} 3$ and so on. The additive metrics were considered due to the hypothesis by Gibson et al. [11] that consideration of NN1 and NN3 together better describes clustering in a settlement and therefore has an influence on fire spread. In order to obtain the coefficients of each independent variable in Equation (9), the least square method has been used and it is given by [34]:

$$
\hat{\beta}=\left(X^{T} X\right)^{-1} X^{T} \hat{y}
$$

where the matrix $X$ contains the spatial metrics of interest (the parameters) for each scenario and the vector $\hat{y}$ contain the actual spread rates predicted by B-RISK for each scenario. Using the Akaike Information Criterion (AIC) [34] the parameters that do not affect the fire spread rates are removed from Equation (9), where it is found that the density and the NN1+NN3 value gave the smallest AIC value (including any other spatial metrics made the AIC value higher). Hence, the final equation to determine potential fire spread rates for informal settlements is as follows:

$$
S_{p}=20.5 D-278.1\left(N N_{1+3}\right)+1742.3
$$

where $D$ is the settlement density (\%) and $N N_{1+3}$ is the distance from the average distance to the first nearest neighbour plus the average distance to the third nearest neighbour $(\mathrm{m})$.

Informal settlement dwelling footprints are available for all informal settlements in Cape Town [33] and using this dataset the following procedure has been applied:

1. PFA's were created;

2. due to the large number of informal settlements in Cape Town, only PFA's larger than 1 ha were selected for subsequent analysis;

3. density and $N N_{1+3}$ have been calculated for each PFA;

4. descriptive statistics of spatial metrics were calculated for both B-RISK scenarios and the PFAs; and

5. Equation (11) has been applied to arrive at a fire spread rate for each PFA.

This method results in a total of 127 PFAs larger than 1 ha for the City of Cape Town. The descriptive statistics reveal that the B-RISK scenarios capture a slightly different range of spatial metrics than is seen in PFAs with the B-RISK range in the spatial metrics calculated as density: $56.4-78.6 \%$; and $\mathrm{NN}_{1+3}$ : 1.13-2.70 m compared with PFAs: density: $65.7-80.9 \%$; and $N N_{1+3}: 0.21-3.78 \mathrm{~m}$. Of the 127 PFAs, 119 and 93 had densities and $N N_{1+3}$ values that fall within the B-RISK scenario range, respectively. A total of $85(67 \%)$ of the PFAs fall within the range of both the spatial metrics used in the B-RISK scenarios. The densities that fall outside of the B-RISK range all exceeded the range used in B-RISK, which is also why, for these values, $N N_{1+3}$ does not exceed the range used in the B-RISK scenario as these represent PFAs where the dwellings are in very close proximity to each other. Thus, the $N N_{1+3}$ spatial metrics place a greater role in excluding PFAs from analysis than density. It can be seen in Figure 17 that where the spatial metrics of PFA overlap with those of the B-RISK scenarios (shown as Reduced PFAs in the figure), the fire spread rate is highest. This implies that Equation (11) predicts high spread rates (greater than $2500 \mathrm{~m}^{2} / \mathrm{h}$ ) more reliably than low spread rates across all PFAs since the equation was developed using scenarios that predict a higher spread rate and those PFAs which likely (but this is yet to be proven) have a lower spread rate were not used in the development of the equation. Note that fire spread rates less than $2500 \mathrm{~m}^{2} / \mathrm{h}$ are not displayed as there is no data in this range for the reduced PFAs. 


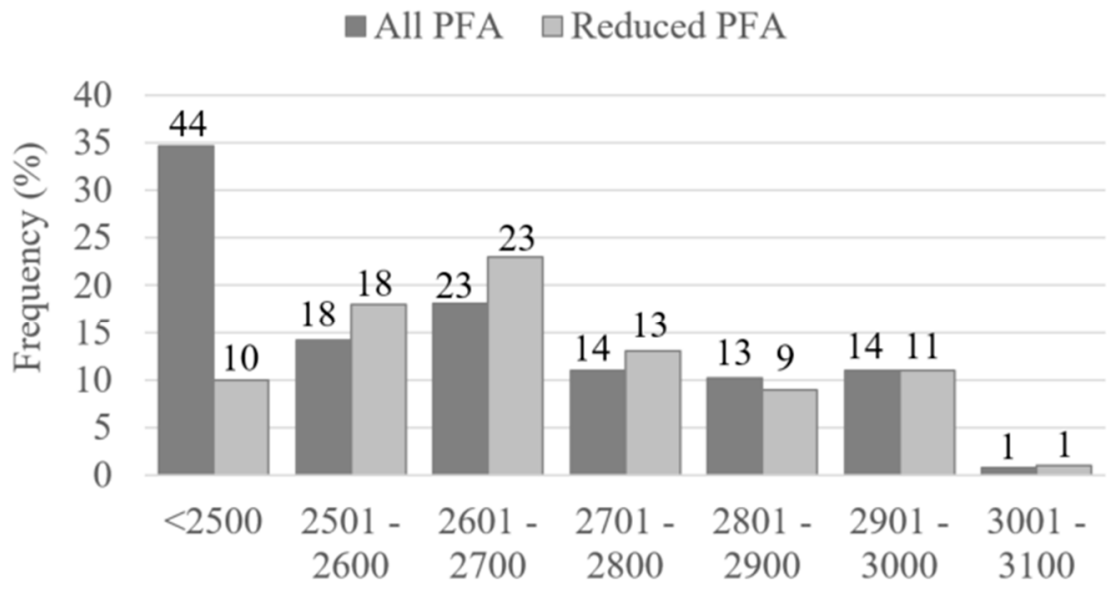

Fire spread rate $\left(\mathrm{m}^{2} / \mathrm{h}\right)$

Figure 17. Histogram showing the predicted fire spread rates for all PFAs greater than 1 ha and also a reduced subset of PFAs where the spatial metrics of the PFA correspond with the spatial metrics used to develop the equation, shown as "Reduced PFA" on the graph. The count is displayed above each bar.

To consider if PFAs with high fire spread rates are in fact affected by large fires in reality, fire spread rates are obtained for burn areas that were previously mapped from satellite imagery [35]. These burn areas are assigned fire spread rates by spatially overlaying the reduced PFAs with the burn areas and assigning the fire spread rate from the PFA to the overlapping burn area. Figure 18 reveals that the burn areas are more likely to be found in PFAs with higher fire spread rates, implying that the fire spread rate equation is correct to some degree but since the fire spread rates are not known for the mapped fires, this can be considered a qualitative rather than quantitative agreement.

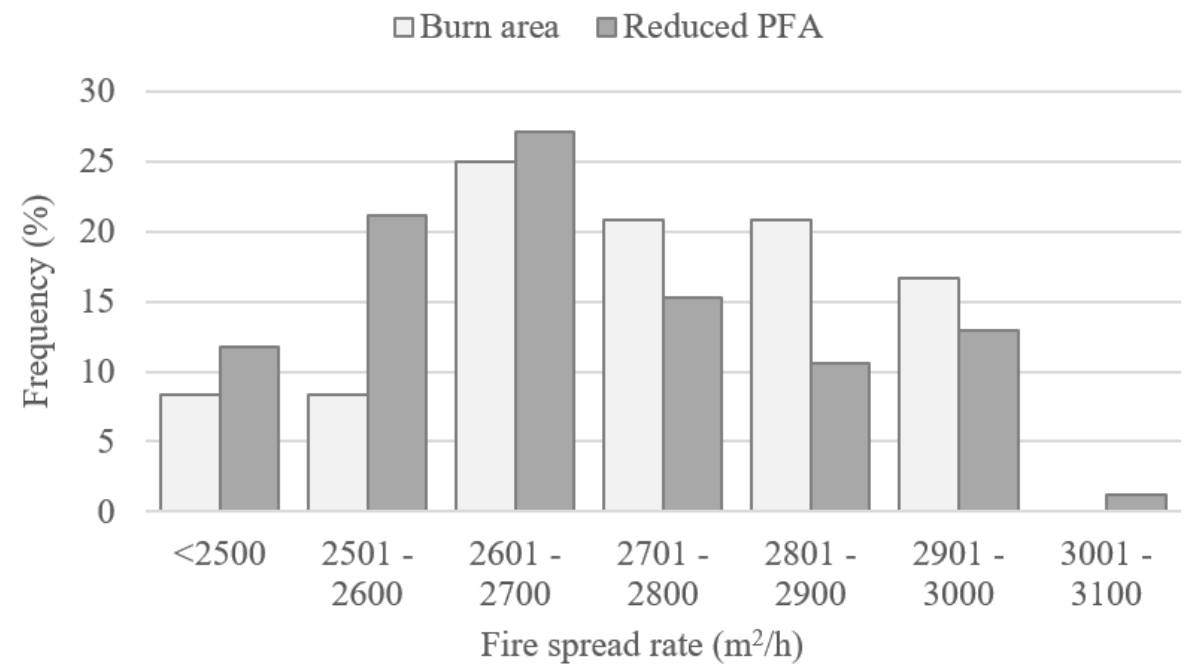

Figure 18. Histogram showing the predicted fire spread rates for the reduced PFAs and burn areas mapped from satellite images.

The PFAs with the top ten (out of 127 PFAs) fire spread rates across all informal settlements within the City of Cape Town are given in Table 3 and the location of the PFAs is shown in Figure 19.

It can be noted that the top 10 PFAs are at or exceed the uppermost fire spread limit calculated in B-RISK $\left(2958 \mathrm{~m}^{2} / \mathrm{h}\right)$ and two of the PFAs in the top 10 (Silvertown and PJS Section) slightly exceed the density used in the development of Equation (11); however, due to their slightly larger $N_{1+3}$ values, these PFAs do not have the highest fire spread rate. The results should therefore be treated as being indicative of settlements at risk of fire spread rather than the fire spread rate be considered 
reliable-not least because the area covered by the top 10 PFAs far exceeds the area covered by 20 dwellings that were used in the development of the equation.

Table 3. PFAs with the highest fire spread rates of the 127 PFAs studied in Cape Town, with their corresponding spatial metrics.

\begin{tabular}{ccccc}
\hline $\begin{array}{c}\text { Settlement Containing } \\
\text { PFA }\end{array}$ & Area $\left(\mathbf{m}^{\mathbf{2}}\right)$ & Density (\%) & $\mathbf{N N}_{\mathbf{1 + 3}} \mathbf{( \mathbf { m } )}$ & $\begin{array}{c}\text { Fire Spread Rate Predicted } \\
\text { by Equation } \mathbf{( 1 1 )}\left(\mathbf{m}^{\mathbf{2}} \mathbf{h}\right)\end{array}$ \\
\hline YAB Section & 10,143 & 77.9 & 1.21 & 3002 \\
\hline K2 Section & 12,156 & 76.6 & 1.27 & 2960 \\
\hline Dunoon School Site & 25,264 & 77.1 & 1.31 & 2957 \\
\hline WB Section & 12,527 & 75.1 & 1.21 & 2942 \\
\hline Kosovo (1) & 90,243 & 75.6 & 1.28 & 2935 \\
\hline Silvertown & 28,124 & 79.7 & 1.6 & 2928 \\
\hline PJS Section & 33,884 & 80.9 & 1.7 & 2927 \\
\hline Phola Park-Philippi & 28,344 & 75.8 & 1.3 & 2926 \\
\hline Masiphumelele & 60,411 & 77.2 & 1.4 & 2923 \\
\hline Kosovo (2) & 23,663 & 77.3 & 1.5 & 2920 \\
\hline
\end{tabular}

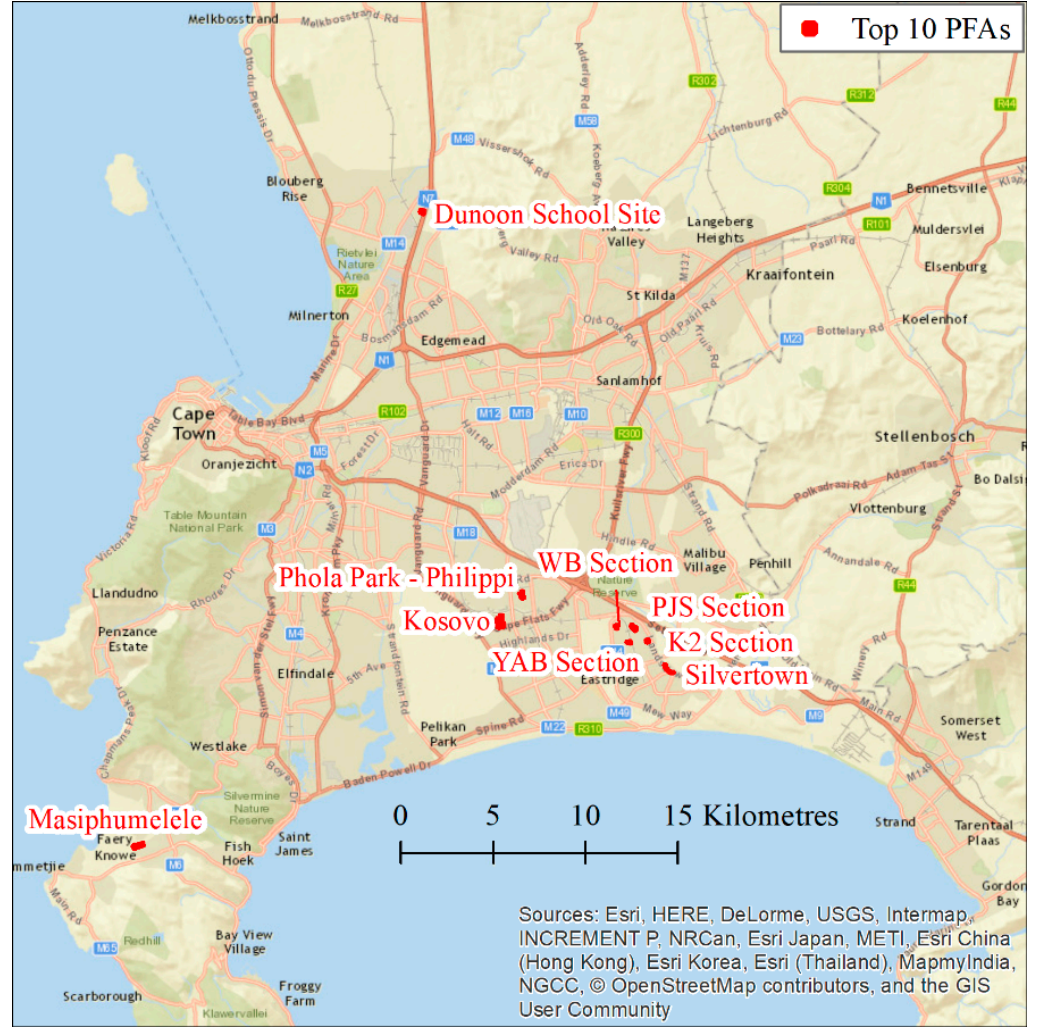

Figure 19. Location of the top 10 PFAs greater than 1 ha that have the highest fire spread rate (North is at the top of the images).

It should be noted that even informal settlements with a "low" calculated spread rate are likely still at a higher risk of large conflagrations compared to most formal neighbours, because of the inherent nature of these areas (i.e., dwellings are built extremely close to each other and built from highly combustible materials). 
The size and shape of the selected top 10 PFAs are shown in Figure 20. YAB Section (Figure 20a), although the PFA with the highest fire spread rate, is the smallest of the top 10 PFAs with an area of just over 1 ha. Masiphumelele and Kosovo are the largest PFAs in the top 10 and the occurrence of fires in these settlements is documented [35] and displayed in Figure 20b,c, respectively. This implies that the size of the PFA should be considered together with the calculated fire spread rates when assessing the particular risk of a settlement. Since the B-RISK scenarios contained only 20 dwellings, and radial fire spread $\left(\mathrm{m}^{2} / \mathrm{h}\right)$ is assumed: as the fire grows in a larger settlement, the fire spread rate will increase. Furthermore, the shape of a settlement will play a role too, since as radial fire spread is assumed, once the fire front reaches the boundary of a settlement, the fire spread rate will change from "radial" to linear along the length of the settlement's boundary. In a settlement that has a high perimeter-to-area ratio, the fire will reach an edge beyond which the fire can no longer grow [36] and, at that point, the fire spread rate will become linear. The current modelling does not consider this.

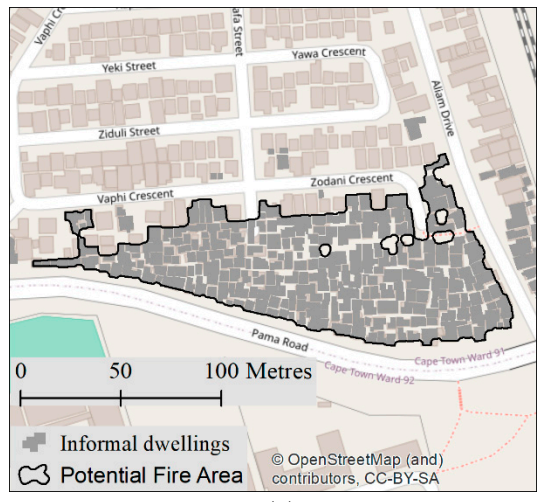

(a)

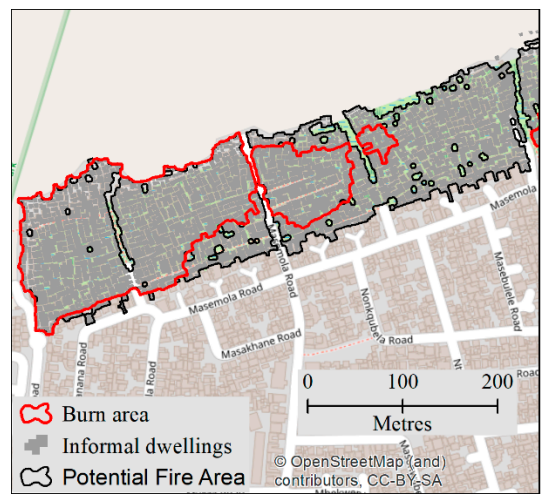

(b)

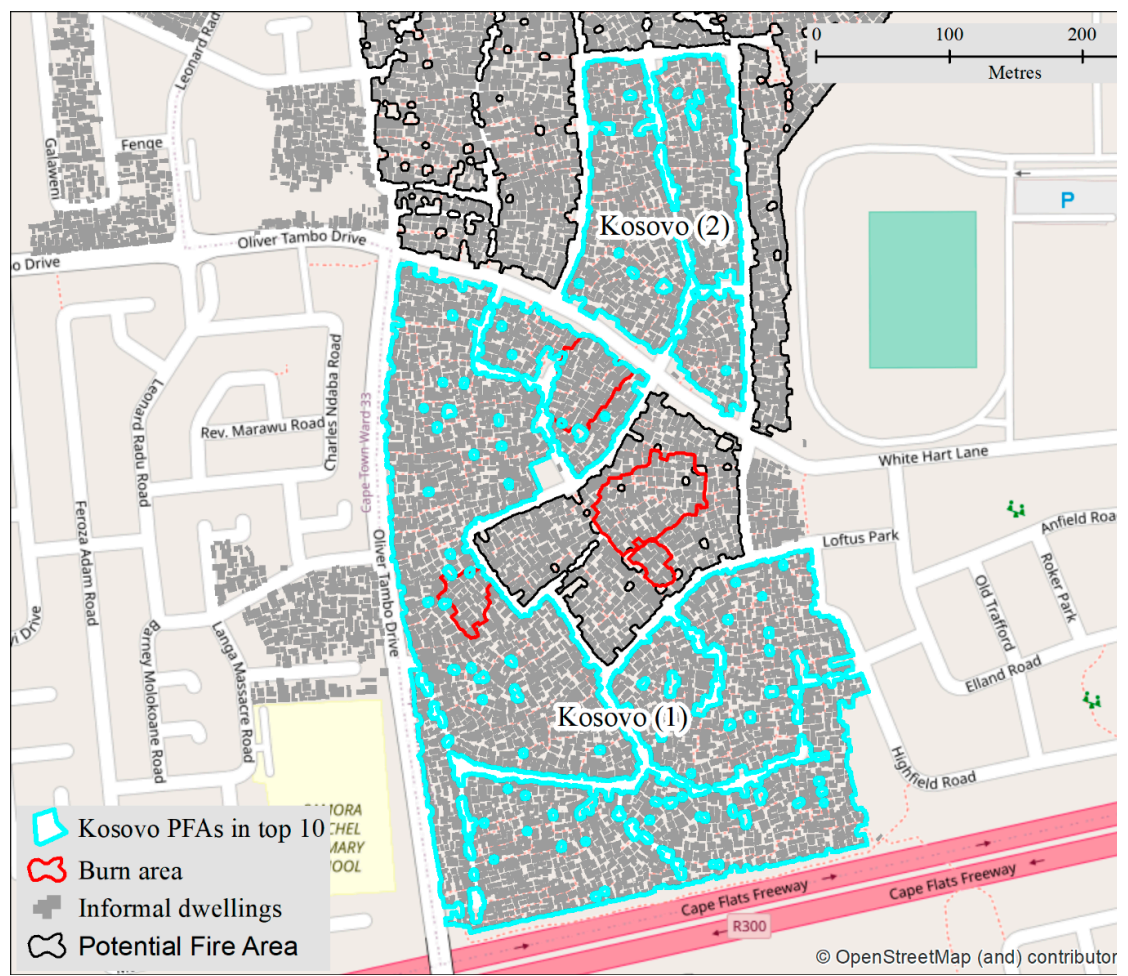

(c)

Figure 20. Selected PFAs in the top 10. (a) PFA with the highest fire spread rate-YAB Section; (b) Masiphumelele, demonstrating the fire occurrence within a PFA with a high fire spread rate; (c) the two PFAs in the top 10 located in Kosovo, a known informal settlement fire hot spot. Burn scars from known previous fires are indicated in red. 
As expected, the equation produces fire spread rates that fall within realistic ranges where the spatial metrics matched those used in the equation's development. Since the ranges used to develop the equation fell in the high fire spread rate side of the spectrum, the PFAs highlighted as being at high risk are likely to reflect reality; also, fires mapped using satellite imagery overlap with the high fire spread rate PFAs but in the absence of a complete fire location and size database, it is impossible to use this as anything other than a qualitative agreement. Fire departments should thus be encouraged to collect accurate spatial locations (GPS coordinates) when they respond to fires as this will enable more accurate modelling, which, in turn, will inform better fire response management.

Although the fire spread rate equation shows promise, this equation is not yet well enough refined to determine actual fire spread rates but rather indicates where settlements at higher risk of fire spread are located. The assumption of radial fire spread in the modelling has been mentioned and the shape of the settlements is likely to have an impact on the rate of fire spread with elongated settlement representing less of a fire spread risk than more compact settlements. Additionally, it should be considered to assign weight values to different settlement sizes, since large settlements have the potential to become larger conflagrations. Finally, it is unknown how well the model performed for settlements with spatial metrics outside the range of those used to develop Equation (11). Finally, B-RISK currently only allows for rectangular-shaped dwellings and the reality of what is found in informal settlements is different. Thus, at this stage, only approximations of a narrow range of real-life dwellings have been included in the equation.

This research represents positive progress, however more work is needed before this method can be used with confidence in real-world scenarios. For future research, it is recommended that (1) a larger variety of B-RISK simulations should be simulated to capture the full range of spatial metrics in informal settlements of Cape Town; (2) explore the influence of settlement shape on the fire spread rate; (3) increase the number of dwellings in the B-RISK simulations to capture nuances in the fire spread risk when compared to the size of the settlement; and (4) improve the B-RISK capability to automate the modelling process.

\section{Future Considerations}

There have been a number of assumptions and simplifications made throughout this paper and these have been highlighted throughout the paper. However, the hope is that the methodologies developed in this paper would ultimately be of use for real settlements as a useful tool for fire fighters and local municipalities. In order to achieve this, it is important that future work refines the methodology by developing more robust methods for the assumptions made. As more data becomes available from informal settlement dwelling experiments and from real fire incidents, the method discussed in this work can be calibrated and updated to account for more variables. Before B-RISK can be used in practice to simulate informal settlement fire spread rates and to determine settlements at risk, the following are some considerations that need to be implemented or investigated in future versions:

(a) the radiation emitted from dwellings could be calculated in a similar manner proposed by Equation (5) in this work. Hence, each wall of the ISD will thus emit a different incident heat flux based on the wall geometry (e.g., a wall with a window opening will radiate more energy compared to a wall with no openings);

(b) the ignition criteria selected should consider both wind direction and separation distances to determine when the ignition criteria set should be auto- or piloted ignition;

(c) the effect of changes in settlement (terrain) elevations;

(d) a functionality that accounts for irregular shape dwellings;

(e) the ability to include ISDs that are not orthogonal to each other in the domain;

(f) the impact of convective cooling/heating; and

(g) the impact of combustible materials placed between ISDs. 


\section{Conclusion}

This paper investigates a semi-probabilistic and spatial metrics methodology for predicting and mapping fire spread in informal settlements, considering a range of phenomena needed in the development of such a tool. The effect of the ignition properties used in B-RISK on fire spread rates between informal settlement dwellings (ISDs) was studied, based on the ignition criteria set (FTP value, FTP index and critical heat flux) of a variety of combustibles typically found in informal settlements. The current semi-probabilistic informal settlement fire spread model, proposed in previous research by the authors, was verified against a 20-dwelling full-scale informal settlement fire experiment, where the 20 dwelling B-RISK simulation shows a good correlation with the experiment. A limited parametric study of the 20-dwelling simulation was conducted, which highlights the effect of the ignition criteria set used. A number of simulations for a real informal settlement fire, with relatively good data, were then run with a variety of ignition properties of typical cladding and lining materials used in informal settlements. The results show that the ignition properties (hence the lining and cladding material used in ISDs) have a significant effect on the rate of fire spread and can increase the fire spread rate by more than $90 \%$.

The paper then takes the next step in developing a tool to identify settlements and areas in settlements most at risk, by post-processing the B-RISK output data to generate colour maps of the linear fire line progression rates and spread patterns. Colour maps of the 20-dwelling experiment and parametric simulations were created, showing that for fire spread not to occur, a critical separation distance of around $4.2 \mathrm{~m}$ between dwellings is necessary, based on these simulations and the parameters used. This is larger than the previously proposed separation distance of $3.8 \mathrm{~m}$, because the wind effect and the influence of multiple dwellings burning at the same time were not previously considered, but are accounted for in this work. A next step to this work would be to provide colour maps (risk maps) for large informal settlements to determine which settlements are most at risk and also to identify "hot spots" within settlements.

The use of B-RISK to produce a fire spread rate equation using spatial metrics has been demonstrated. A total of 500 simulations using 25 settlement scenarios were run in B-RISK and the average fire spread rates were calculated. Analysis of the spatial metrics calculated for each scenario reveal that settlement density and the average distance to the first nearest neighbour plus the distance to the third nearest neighbour are the most influential spatial metric in predicting fire spread rate. The fire spread rate equation was applied to informal dwellings in Cape Town and 127 potential fire spread areas (PFA) larger than 1 ha were found. The PFAs with the 10 highest fire spread rates are presented and some of these PFAs are located in settlements known to be fire hot spots. Due to the high level of uncertainty and variability associated with informal settlements, further research is required to fine tune the equation to a more complete range of informal settlement layouts and to account for the assumptions made in the modelling. Factors that are difficult to quantify in settlements include the influence of suppression (from residents and firefighters), branding, combustible material stored between dwellings, the presence of explosive items such as LPG cylinders and even fuel loads that move during events as people evacuate with their possessions. However, the spread rates provide useful benchmarks and comparisons from which informed decisions can be made, and with time the predictions will be refined. However, this work represents a substantial step forward (a) in linking outputs from the B-RISK simulations to outputs for GIS to help identify settlements at risk of fire spread, and (b) to create a risk management tool for government and local authorities.

Author Contributions: Conceptualization, A.C., L.G., C.W. and M.S.; formal analysis, A.C. and L.G.; funding acquisition, R.W. and D.R.; methodology, A.C., L.G., C.W. and M.S.; software, A.C. and L.G.; visualization, A.C. and L.G.; writing-original draft, A.C.; writing-review and editing, A.C., L.G., C.W., M.S., R.W. and D.R. All authors have read and agreed to the published version of the manuscript.

Funding: The authors would like to acknowledge the financial support of the Lloyd's Register Foundation under the "Fire Engineering Education for Africa" project (Grant GA 100093), the IRIS-Fire GCRF project from the UK (Engineering and Physical Sciences Research Council (Grant no.: EP/P029582/1)), as well as the Royal 
Academy of Engineering / Lloyd's Register Foundation Engineering X programme under grant "A Fire Safe Africa" (Grant ESMN1921 \1\141).

Acknowledgments: The authors would also like to gratefully acknowledge BRANZ in New Zealand for their support enabling modifications to the B-RISK model.

Conflicts of Interest: The authors hereby acknowledge the financial contribution of the following organisations in the completion of this work: the Lloyd's Register Foundation under the "Fire Engineering Education for Africa" project (Grant GA 100093), the IRIS-Fire GCRF project from the UK (Engineering and Physical Sciences Research Council (Grant no.: EP/P029582/1)), as well as the Royal Academy of Engineering / Lloyd's Register Foundation Engineering X programme under grant "A Fire Safe Africa" (Grant ESMN1921 \1\141). None of these organisations have vested interests in the work and no conflicts of interest exist in the publication of this work.

\section{References}

1. FPASA. SA Fire Loss Statistics 2016; FPASA: Boksburg, South Africa, 2018.

2. World Health Organization. Burns; WHO: Geneva, Switzerland, 2018.

3. A News, Favela in Flames: Aerial Footage Shows Fire Ripping through Brazilian Slum. 2016. Available online: https://www.abc.net.au/news/2016-09-14/fire-sweeps-through-sao-paulo-favela/7843336 (accessed on 9 April 2020).

4. Kahanji, C.; Walls, R.S.; Cicione, A. Fire spread analysis for the 2017 Imizamo Yethu informal settlement conflagration in South Africa. Int. J. Disaster Risk Reduct. 2019, 39. [CrossRef]

5. Wang, Y.; Beshir, M.; Cicione, A.; Hadden, R.; Krajcovic, M.; Rush, D. A full-scale experimental study on single dwelling burning behavior of informal settlement. Fire Saf. J. 2020, 103076. [CrossRef]

6. Cicione, A.; Walls, R.S. Towards a simplified fire dynamic simulator model to analyse fire spread between multiple informal settlement dwellings based on full-scale experiments. Fire Mater. 2020, 1-17. [CrossRef]

7. Cicione, A.; Beshir, M.; Walls, R.S.; Rush, D. Full-Scale Informal Settlement Dwelling Fire Experiments and Development of Numerical Models. Fire Technol. J. 2019. [CrossRef]

8. de Koker, N.; Walls, R.; Cicione, A.; Sander, Z.; Loffel, S.; Claasen, J.; Fourie, S.; Croukamp, L.; Rush, D. 20 Dwelling Large-Scale Experiment of Fire Spread in Informal Settlements. Fire Technol. 2020. [CrossRef]

9. Cicione, A.; Walls, R.S.; Kahanji, C. Experimental study of fire spread between multiple full scale informal settlement dwellings. Fire Saf. J. 2019, 105, 19-27. [CrossRef]

10. Cicione, A.; Wade, C.; Spearpoint, M.; Gibson, L.; Walls, R.S.; Rush, D. A preliminary investigation to develop a semi-probabilistic model of informal settlement fire spread using B-RISK. Fire Saf. J. 2020, 103115. [CrossRef]

11. Gibson, L.; Cicione, A.; Stevens, S.; Rush, D. The influence of wind and the spatial layout of dwellings on fire spread in informal settlements in Cape Town. Fire Saf. J. 2020. submitted.

12. Walton, W.D.; Carpenter, D.; Wood, C. Zone Computer Fire Models for Enclosures. In SFPE Handbook of Fire Protection Engineering, 5th ed.; Springer: New York, NY, USA, 2016; pp. 1025-1033. [CrossRef]

13. Wade, C.; Baker, G.; Frank, K.; Harrison, R.; Spearpoint, M. B-RISK User Guide and Technical Manual, BRANZ Study Report SR364; BRANZ: Porirua, New Zealand, 2016.

14. Sazegara, S.; Spearpoint, M.; Baker, G. Benchmarking the Single Item Ignition Prediction Capability of B-RISK Using Furniture Calorimeter and Room-Size Experiments. Fire Technol. 2017, 53, 1485-1508. [CrossRef]

15. Tohir, M.Z.M. The Capability of B-RISK Zone Modelling Software to Simulate BRE Multiple Vehicle Fire Spread Test. In Proceedings of the Asian Simulation Conference, Melaka, Malaysia, 27-29 August 2017.

16. Building Research Establishment (BRE). Fire Spread in Car Parks; Building Research Establishment: London, UK, 2010.

17. Heskestad, G. Fire Plumes, Flame Height, and Air Entrainment. In SFPE Handbook of Fire Protection Engineering, 4th ed.; Springer: Quincy, MA, USA, 2008; pp. 2-20.

18. Oka, Y.; Sugawa, O.; Imamura, T.; Matsubara, Y. Effect of Cross-Winds to Apparent Flame Height and Tilt Angle from Several Kinds of Fire Source. In SFPE Handbook of Fire Protection Engineering; Springer: Quincy, MA, USA, 2003; pp. 915-926. [CrossRef]

19. Cicione, A.; Walls, R.; Sander, Z.; Quiroz, N.F.; Narayanan, V.; Stevens, S.; Rush, D. The effect of separation distance between informal dwellings on fire spread rates based on experimental data and analytical equations. Fire Technol. 2020, 1-37. [CrossRef]

20. Tewarson, A. Generation of Heat and Chemical Compounds in Fires. In SFPE Handbook of Fire Protection Engineering, 3rd ed.; DiNenno, P., Ed.; Springer: Quincy, MA, USA, 2016; pp. 277-324. [CrossRef] 
21. Shields, T.J.; Silcock, G.W.; Murry, J.J. Evaluating ignition data using the flux time product. Fire Mater. 1994, 18, 243-254. [CrossRef]

22. Wang, Y.; Bertrand, C.; Beshir, M.; Kahanji, C.; Walls, R.; Rush, D. Developing an experimental database of burning characteristics of combustible informal settlement dwelling materials. Fire Saf. J. 2019. [CrossRef]

23. Wang, Y.; Rush, D. Cone Calorimeter Tests of Combustible Materials Found in Informal Settlements; Edinburgh DataShare, University of Edinburgh: Edinburgh, UK, 2019. [CrossRef]

24. Rush, D.; Gibson, L.; Bankoff, G.; Walls, R.; Spinardi, G.; Cooper-Knock, S.; Twigg, J.; Al, E. Fire Risk Reduction in an Urbanizing World. In United Nations Office for Disaster Risk Reduction; United Nations: Geneva, Switzerland, 2019.

25. Walls, R.; Zweig, P. Towards sustainable slums: Understanding fire engineering in informal settlements, Sustain. Vital Technol. Eng. Inform. 2016, 4, 1-5.

26. Baker, G.; Spearpoint, M.; Fleischmann, C.; Wade, C. Selecting an ignition criterion methodology for use in a radiative fire spread submodel. Fire Mater. 2011, 35, 367-381. [CrossRef]

27. Babrauskas, V. Heat release rates. In SFPE Handbook of Fire Protection Engineering, 5th ed.; Hurley, M.J., Ed.; Springer: Berlin/Heidelberg, Germany, 2016; p. 829. [CrossRef]

28. Cicione, A.; Walls, R. Estimating time to structural collapse of informal settlement dwellings based on structural fire engineering principles. In Advances in Engineering Materials, Structures and Systems: Innovations, Mechanics and Applications; CRC Press: Boca Raton, FL, USA, 2019.

29. Walls, R.S.; Zweig, P. Towards sustainable slums: Understanding fire engineering in informal settlements. In Proceedings of the International Conference on Sustainable Vital Technologies in Engineering and Informatics, Cairo, Egypt, 7-9 November 2016; pp. 93-98. [CrossRef]

30. Mcgrattan, K.; Mcdermott, R.; Simo, H.; Floyd, J.; Vanella, M.; Weinschenk, C.; Overholt, K. Fire Dynamics Simulator Technical Reference Guide Volume 3: Validation; NIST: Gaithersburg, MD, USA, 2017.

31. Wang, Y.; Gibson, L.; Beshir, M.; Rush, D. Preliminary investigation of critical separation distance between shacks in informal settlements fire. In Proceedings of the 11th Asia-Oceania Symposium on Fire Science and Technology, Taipei, Taiwan, 22-24 October 2018.

32. Gibson, L.; Adeleke, A.; Hadden, R.; Rush, D. Spatial metrics from LiDAR roof mapping for fire spread risk assessment of informal settlements in Cape Town, South Africa. Fire Saf. J. 2020, 103053. [CrossRef]

33. School of Engineering, University of Edinburgh. Infrastructure and Environment, Dwelling OutlineInformal Settlements of Cape Town. 2020. Available online: https://datashare.is.ed.ac.uk/handle/10283/3560 (accessed on 3 November 2020).

34. Montgomery, D.C.; Jennings, C.L.; Kulahci, M. Introduction Time Series Analysis and Forecasting; Wiley: Hoboken, NJ, USA, 2016.

35. Gibson, L. Informal Dwelling Fires, 2009-2015, City of Cape Town, 2009-2015; School of Engineering, University of Edinburgh: Edinburgh, UK, 2020.

36. Stevens, S.; Gibson, L.; Rush, D. Conceptualising a GIS-based risk quantification framework for fire spread in informal settlements: A Cape Town case study. Int. J. Disaster Risk Reduct. 2020, 50, 101736. [CrossRef]

Publisher's Note: MDPI stays neutral with regard to jurisdictional claims in published maps and institutional affiliations.

(C) 2020 by the authors. Licensee MDPI, Basel, Switzerland. This article is an open access article distributed under the terms and conditions of the Creative Commons Attribution (CC BY) license (http://creativecommons.org/licenses/by/4.0/). 